\title{
One-pot two-step process for direct propylene oxide production catalyzed by bi-functional Pd(Au)@TS-1 materials
}

\author{
Alejandro Prieto ${ }^{a}$, Miguel Palomino ${ }^{a}$, Urbano Díaz ${ }^{a^{*}}$, Avelino Corma ${ }^{a}$ \\ a Instituto de Tecnología Química (UPV-CSIC), Universitat Politècnica de Valéncia - Consejo \\ Superior de Investigaciones Científicas, Avenida de los Naranjos s/n., 46022 Valencia, Spain. \\ E-mail: udiaz@itq.upv.es
}

\begin{abstract}
Different bi-functional materials (Pd(Au)@TS-1) based on metallic nanoparticles supported onto active nanocrystalline titanium silicalite (TS-1) zeolites were synthesized, characterized and used as recyclable heterogeneous catalysts for direct propylene oxide production from hydrogen, oxygen and propylene through one-pot two-step consecutive process. These catalysts allowed carrying out the combined reaction where metallic nanoparticles catalyzed the formation of in situ $\mathrm{H}_{2} \mathrm{O}_{2}$ that was the necessary intermediate for propylene epoxidation catalyzed by active TS- 1 nanocrystalline support. Several variables were considered such as use of supercritical $\mathrm{CO}_{2}$ conditions, modifiable content of metallic species, and presence of additional co-solvents, surface acidity inhibitors and $\mathrm{H}_{2} \mathrm{O}_{2}$ stabilizers. Reusability and stability of the bi-functional catalyst was showed through consecutive catalytic cycles.
\end{abstract}

Keywords: Propylene oxide; Bi-functional catalysts; Supercritical $\mathrm{CO}_{2}$ conditions; Palladium nanoparticles; Gold nanoparticles; Titanium silicalite. 


\section{Introduction}

Propylene oxide (PO) is an important monomer in chemical industry due to the presence of highly reactive oxyranic group, which lead to many different organic products under the appropriate conditions. For this reason, PO is currently being used mainly for the synthesis of polyurethane foams, resins and propylene glycol, being its worldwide production about 7.5 million tons per year, and this market is annually growing 4-5\% [1, 2]. However, although the most convenient production process for PO synthesis would be the direct oxidation of propylene with oxygen [3], results in this direction have been poor [4] and the development of safe and low contaminating propylene oxide synthesis process is still a matter of study. The nowadays production processes are mainly chlorohydrins and organic hydroperoxide processes, but both have important drawbacks. In the case of the chlorohydrins process, stoichiometric amounts of $\mathrm{CaCl}_{2}$ are produced together with a large amount of waste water. On the other hand, hydroperoxide process produces styrene or isobutylene together with PO in stoichiometric ratio, two compounds severely affected by market trends $[5,6]$.

Moreover, although heterogeneous catalysts can be alternatively used in the hydroperoxide method [7], PO production is being carried out in presence of molybdenumtype homogeneous catalyst [8]. In this sense, the use of homogeneous catalysts implies difficult and expensive catalyst recoveries, being affected by poor thermal stability. As alternative, heterogeneous catalysts have important advantages, including easy and cheap catalyst separation and low costs associated to catalyst losses, factors which enhance the catalyst reusability [9], making hence desirable the development of highly active and selective heterogeneous catalysts [10] for effective direct PO production.

In this way, titanium silicalite-1 (TS-1), firstly synthesized by Taramasso et al. [11] and optimized by different synthesis methods, has been an excellent solid catalyst for propylene epoxidation, using hydrogen peroxide $\left(\mathrm{H}_{2} \mathrm{O}_{2}\right)$ as external oxidizing agent. However, $\mathrm{H}_{2} \mathrm{O}_{2}$ is currently obtained at industrial level from anthraquinone, using heterogeneous catalysts containing $\mathrm{Pd}$ or $\mathrm{Ni}$ [12], favoring high waste generation due to the use of toxic solvents and extensive purification methods, besides the high initial required budget and its high operation costs [13]. All these drawbacks increase the $\mathrm{H}_{2} \mathrm{O}_{2}$ market value up to the PO value, making this process non-viable [14] unless $\mathrm{H}_{2} \mathrm{O}_{2}$ is formed in-situ and non-expensive intermediate and purification steps are required. Advances in this sense were achieved with the HPPO process [15], where $\mathrm{H}_{2} \mathrm{O}_{2}$ is produced during the reaction in one separated reactor, through the anthraquinone route, and then is fed to an additional reactor, in which the propylene epoxidation occurs.

However, although HPPO approach represents an improvement of previous PO synthesis methodologies, the process requires the use of two different catalysts and two different individual reactors. A further improvement of the current methodology would be the development of a process in which both the $\mathrm{H}_{2} \mathrm{O}_{2}$ synthesis from $\mathrm{H}_{2}$ and $\mathrm{O}_{2}$ and the propylene epoxidation reactions are catalyzed by heterogeneous bi-functional catalysts, in a one-pot direct reaction. Considering that catalysts containing $\mathrm{Pd}$ [16] or $\mathrm{Au}$ [17] nanoparticles (NPs) favor the $\mathrm{H}_{2} \mathrm{O}_{2}$ formation, Hayasahi et al. [18], showed that bifunctional materials formed by Au NPs supported onto titania matrix were able to catalyze the reaction between propylene 
and in-situ generated $\mathrm{H}_{2} \mathrm{O}_{2}$ from $\mathrm{H}_{2}$ and $\mathrm{O}_{2}$ with high selectivities in gaseous phase and atmospheric pressure, especially when Au NPs with averages sizes between 2 and $5 \mathrm{~nm}$ were incorporated [19]. However, it has also been observed that ${\mathrm{Au} @ \mathrm{TiO}_{2}}_{2}$ catalysts suffer deactivation phenomenon and its catalytic activity decreases with time [20]. For this reason, taking into account the high catalytic performance of TS-1 catalysts, would be interesting to use this kind of catalysts instead of $\mathrm{TiO}_{2}$ as supports for the Au NPs deposition. In this regard, Yap et al. [21] showed that Au@TS-1 catalysts, containing Au NPs with average sizes between 1 and $2 \mathrm{~nm}$, were the most active when TS-1 is used as supporting matrix, allowing to achieve higher selectivities, being these results consistent with those reported by Lee et al. [22], who also reported that $1 \mathrm{~nm}$ Au NPs were the most active NPs when TS-1 catalysts were used as support. Furthermore, Tsubaki et al. showed that catalysts containing both Pd and Au were also able to generate $\mathrm{PO}$ from in-situ generated $\mathrm{H}_{2} \mathrm{O}_{2}$ in gaseous phase, showing the benefits of combining them [23]. However, though results obtained up to now are highly promising due to the high PO selectivities, propylene conversions under $8 \%$ were obtained, being observed a decrease in selectivity at higher conversions [21, 24, 25, 26, 27]. Moreover, in order to improve the catalytic results, it would be desirable to increase the hydrogen and oxygen amounts in the mixture. Howbeit, the broad flammability range of hydrogen-oxygen mixtures, which could be explosive with hydrogen concentrations between 3.8 and 95.5\% [28], requires to take greater precautions.

Taking into account all these issues, there are several pathways to increase the amounts of $\mathrm{H}_{2}$ and $\mathrm{O}_{2}$ at the same time that the reaction is kept in non-explosive regime, including the use of capillary micro-channels [29] or supercritical conditions [30]. In the first approach, the use of a miniaturized reactor allows working with hydrogen/oxygen mixtures that would be explosive under standard conditions, leading to an enhancement in the intermediate $\mathrm{H}_{2} \mathrm{O}_{2}$ production step. On the second approach, supercritical carbon dioxide $\left(\mathrm{scCO}_{2}\right)$ could be a possible alternative, due to its interesting properties, including the complete miscibility between $\mathrm{CO}_{2}, \mathrm{H}_{2}$ and $\mathrm{O}_{2}$ in all proportions at supercritical conditions, much higher miscibility even at sub-critical conditions [31] and the reduction of the $\mathrm{H}_{2} / \mathrm{O}_{2}$ flammability range in presence of $\mathrm{CO}_{2}$, both at atmospheric and at high pressure conditions $[30,32]$. Making use of all these advantages, $\mathrm{H}_{2} \mathrm{O}_{2}$ synthesis from $\mathrm{H}_{2}$ and $\mathrm{O}_{2}$ in supercritical media was reported by Chen et al. [33], obtaining high yields when Pd and PdPt@TS-1 catalysts were used. On the other hand, the use of $\mathrm{scCO}_{2}$ as solvent for the epoxidation of propylene with external $\mathrm{H}_{2} \mathrm{O}_{2}$ in presence of TS-1 catalyst has also been reported [34], being even more selective than in conventional reaction conditions.

Considering both the high $\mathrm{H}_{2} \mathrm{O}_{2}$ production and the high selectivity of the epoxidation in $\mathrm{scCO}_{2}$ media together with the inherent safety benefits, the next step would be to carry out the propylene epoxidation with in-situ generated $\mathrm{H}_{2} \mathrm{O}_{2}$ in these conditions, in order to increase the PO yield. In that sense, promising results have been obtained with PdPt@TS-1 catalysts in presence of $\mathrm{scCO}_{2}$ as solvent $[35,36]$, showing the benefits of this approach. Furthermore, PdAu@TS-1 catalysts have also shown a high catalytic activity on the $\mathrm{H}_{2} \mathrm{O}_{2}$ direct synthesis reaction in the presence of a mixture of $\mathrm{CO}_{2}$ and methanol as solvents [37]. On the other hand, the addition of small amounts of gold to Pd@TS-1 appears to be disadvantageous for the PO production from in-situ generated $\mathrm{H}_{2} \mathrm{O}_{2}$ in liquid phase [38], increasing the selectivity towards propane. However, taking into account the high selectivity of PdAu@TS-1 catalysts for the 
synthesis of $\mathrm{H}_{2} \mathrm{O}_{2}$, it would be interesting to study the best reaction conditions for PO direct synthesis in batch conditions, under $\mathrm{scCO}_{2}$ media, using this type of catalysts.

In the present work, several bi-functional materials based on $\mathrm{Au}$ and $\mathrm{Pd}(\mathrm{Au}) \mathrm{NPs}$ deposited over TS-1 have been prepared and their catalytic activity has been studied on the propylene epoxidation reaction with in-situ generated $\mathrm{H}_{2} \mathrm{O}_{2}$ from $\mathrm{H}_{2}$ and $\mathrm{O}_{2}$. The catalysts were able to carry out the one-pot two-step consecutive process where the metallic NPs catalyze the formation of $\mathrm{H}_{2} \mathrm{O}_{2}$ which was used as oxidizing reagent for propylene epoxidation catalyzed by TS-1 nanocrystals. The effect of supercritical $\mathrm{CO}_{2}$ as solvent, during the reaction process, together with the use of additional co-solvents was considered, seeking to enhance and optimize the performances and selectivity for direct PO synthesis. Physico-chemical modification of the bi-functional catalysts through the variable content in Pd and Au NPs, use of surface acidity inhibitors and addition of low amounts of $\mathrm{H}_{2} \mathrm{O}_{2}$ stabilizers were also considered, together with catalyst stability studies through consecutive regeneration processes and catalytic reuses. 


\section{Experimental}

\section{Catalysts preparation}

\section{Synthesis of nanocrystalline TS-1}

The preparation of nanocrystalline TS-1 zeolite, used as inorganic support, was carried out by combination of micellar and hydrothermal synthesis methodologies [39].

Specifically, $2.0 \mathrm{~g}$ of Tween 20 (s.d. FINE CHEM.) were dissolved in $32 \mathrm{~g}$ of distilled water. This surfactant solution was added to $19.2 \mathrm{~g}$ of tetrapropylammonium hydroxide (TPA$\mathrm{OH}, 32 \%$ aqueous solution, Alfa Aesar) under mild stirring, resulting in the formation of a clear transparent solution. $36 \mathrm{~g}$ of tetraethyl orthosilicate (TEOS, Aldrich) were added to the above micellar solution in a dropwise fashion under vigorous stirring. The stirring was continued for 1 h. After, $1.8 \mathrm{~g}$ of tetra $n$-butyl titanate (TNBT, Aldrich) in $9.1 \mathrm{~g}$ of isopropyl alcohol (IPA, s.d. FINE CHEM.) were added dropwise under vigorous stirring, being continued for additional $1 \mathrm{~h}$. The resulting mixture still remained clear, exhibiting a molar composition of $0.03 \mathrm{TiO}_{2}$ : $\mathrm{SiO}_{2}$ : 0.12 TPAOH : 0.009 Tween $20: 0.88$ IPA : $14.45 \mathrm{H}_{2} \mathrm{O}$. The mixture was then crystallized at 160 ㅇ $\mathrm{C}$ for $18 \mathrm{~h}$ under autogeneous pressure. The product was recovered by centrifugation, washed with distilled water and dried $(100 \circ \mathrm{C}, 12 \mathrm{~h})$. The calcination was carried out in a muffle furnace at $350^{\circ} \mathrm{C}$ for $2 \mathrm{~h}$ (heating rate of $2.7^{\circ} \mathrm{C} / \mathrm{min}$ ) and finally at $550^{\circ} \mathrm{C}$ for $3 \mathrm{~h}$ (heating rate $3.3 \circ \mathrm{C} / \mathrm{min})$.

\section{Metallic nanoparticles deposition}

Bi-functional catalysts were prepared by sol-immobilization method following the methodology described by Dimitratos et al. [40]. In detail, for the preparation of $\mathrm{Pd}(\mathrm{Au}) @ \mathrm{TS}-1$ catalysts, containing $1 \% \mathrm{Pd}$ and $1 \% \mathrm{Au}, 16.6 \mathrm{mg}$ of $\mathrm{PdCl}_{2}(\mathrm{ABCR})$ and $20 \mathrm{mg}$ of $\mathrm{HAuCl}_{4} \cdot 3 \mathrm{H}_{2} \mathrm{O}$ (Aldrich) were dissolved in $0.5 \mathrm{~g}$ and $1.0 \mathrm{~g}$ of water, respectively. Then, both solutions were added to a freshly prepared $1 \%$ wt polyvinyl alcohol water solution (Aldrich, PVA/(Au $+\mathrm{Pd}$ ) (wt/wt) $=1.2$ ), followed by the addition of $0.1 \mathrm{M} \mathrm{NaBH}_{4}$ water solution (Aldrich, $\mathrm{NaBH}_{4} /(\mathrm{Au}+$ $\mathrm{Pd})(\mathrm{mol} / \mathrm{mol})=5)$. After $30 \mathrm{~min}$ under vigorous agitation, the solution was acidified to $\mathrm{pH}=1$ with sulfuric acid, and $1 \mathrm{~g}$ of previously prepared and calcined TS-1 was added. After $2 \mathrm{~h}$ of vigorous stirring, the mixture was filtered, and the recovered catalyst was washed with distilled water until $\mathrm{pH}=7$ and dried at $100 \circ \mathrm{C}$ overnight. The catalyst was calcined at $200 \circ \mathrm{C}$ under air for $3 \mathrm{~h}$. It is important to remark that the catalysts used without previous reduction treatment did not show any catalytic activity on PO production (results not shown). For this reason, and unless otherwise stated, all the catalysts were reduced for 3 hours in the presence of $\mathrm{H}_{2}$ at room temperature just before each catalytic test, as previously reported [36].

The general acronym of the synthesized bi-functional catalysts was PdxxAuyy@TS-1, being $x x$ and $y y$ indicative of the metallic amount supported onto TS-1 support, i. e., 02, 04, 05 and 10 would correspond to $0.2 \% \mathrm{wt}, 0.4 \% \mathrm{wt}, 0.5 \% \mathrm{wt}$ and $1.0 \% \mathrm{wt}$ of metal, respectively. 


\section{Catalysts characterization}

XRD analysis was carried out with a PANalytical X'Pert PRO diffractometer in the BraggBrentano geometry using $\mathrm{Cu} \mathrm{K} \alpha$ radiation. $\mathrm{C}, \mathrm{N}$ and $\mathrm{H}$ contents were determined with a Carlo Erba 1106 elemental analyzer, while $\mathrm{Pd}$ and $\mathrm{Au}$ contents were obtained by means of atomic absorption spectroscopy (Spectra AA 10 Plus, Varian). A Cary 5 spectrometer equipped with a diffuse reflectance accessory was used for UV measurements. Volumetric analyses were performed by nitrogen adsorption isotherms at 77K with a Micromeritics ASAP2010. Before the measurements, the samples were outgassed for 12 hours at $400^{\circ} \mathrm{C}$. The BET specific surface area [41] was calculated from the nitrogen adsorption data in a relative pressure range from 0.04 to 0.2 . The total pore volume [42] was obtained from the amount of $\mathrm{N}_{2}$ adsorbed at a relative pressure of $\sim 0.95$. External surface area and micropore volume were estimated with the $t$-plot method in the $t$ range from 3.5 to 5 . The pore diameter and the pore size distribution were obtained following the Barret-Joyner-Halenda (BJH) method [43] on the adsorption branch of the isotherms. Scanning and transmission electron micrographs (SEM and TEM) were obtained in a JEOL6300 and Philips CM10 (100kV) microscopes, respectively. Before TEM observation, the samples were prepared by suspending the solid in water, ultrasonicating for $30 \mathrm{~min}$ and placing one drop for evaporation on carbon-coated copper grid (300 mesh).

\section{Catalytic tests}

PO synthesis reaction from propylene in presence of ex situ $\mathrm{H}_{2} \mathrm{O}_{2}$, as oxidizing agent, were performed in a $3 \mathrm{~mL}$ round bottom glass reactor in which the stirring was driven by a Teflon-coated magnetic stirrer. Known amounts of TS-1 catalyst $(2.5 \mathrm{mg})$, methanol $(1.2 \mathrm{~g})$, and propylene $(9 \mathrm{mmol})$ were added, followed by the addition of the oxidant, $35 \%$ wt $\mathrm{H}_{2} \mathrm{O}_{2}$ in water $(0.4 \mathrm{mmol})$. Then, the mixture was heated at $60^{\circ} \mathrm{C}$, and the reaction was monitored for 5 h.

The experiments for the direct synthesis of $\mathrm{PO}$ with in situ generated $\mathrm{H}_{2} \mathrm{O}_{2}$ were carried out in a $15 \mathrm{~mL}$ stainless steel reactor which contained a relief valve, for safety. The stirring was driven by a Teflon-coated magnetic stirrer. Known amounts of catalyst $(15 \mathrm{mg})$, acidity inhibitor (ammonium acetate, $0.01 \mathrm{~g}$ ) and co-solvent ( $0.2 \mathrm{~g}$ of different co-solvents) were added to the reactor, followed by the addition of propylene $(2 \mathrm{mmol})$ and $\mathrm{CO}_{2}$, reaching carbon dioxide vapor pressure ( $>55$ bar) [44]. Oxygen and hydrogen were added to the reactor by means of high pressure burettes, and then the reactor was heated up to desired temperature (ranging from room temperature to $80^{\circ} \mathrm{C}$, according each experiment). The reaction experiments were carried out for $5 \mathrm{~h}$, unless otherwise stated. At the end of the reaction, the reactor was cooled down and the pressure was slowly released by venting, accumulating the gaseous mixture in an inert gas sampling bag. 3-pentanone was used for recovering any product that could be retained on the reactor walls.

The amount of formed products, i.e., propylene oxide, acetone, propionaldehyde, acrolein, isopropanol, 1-methoxy-2-propanol (MP1), 2-methoxy-1-propanol (MP2), propylene glycol (PG) and propylene carbonate were analyzed using a Shimadzu Gas chromatograph GC2010 Plus provided with FID detector and $20 \mathrm{~m}$ length, $0.10 \mathrm{~mm}$ ID, $0.10 \mu \mathrm{m}$ df. Permabond FFAP column. The amounts of propane and un-reacted propylene, oxygen and hydrogen were analyzed using a Bruker 450-GC which contains two different independent channels. The first one is provided with a thermal conductivity detector (TCD) and three different columns: 
Hayesep N (0.5 m length), Hayesep Q (1.5 m length) and molsieve 13X (1.2 m length), using argon as carrier. The second one is provided with two different flame ionization detectors (FID) and three different columns: capillary column CP-Wax (1 m length and $0.32 \mathrm{~mm}$ ID), CPPorabond $\mathrm{Q}$ ( $25 \mathrm{~m}$ length and $0.32 \mathrm{~mm}$ ID) and CP-Wax ( $5 \mathrm{~m}$ length and $0.32 \mathrm{~mm}$ ID).

Due to the extensive list of possible by-products that have been reported in literature for this reaction, all the products have been calibrated using mixtures with known composition. All the products in the liquid and in the gaseous phases have been identified by comparison with known standards. 


\section{Results and discussion}

\section{Synthesis and characterization of catalysts}

The bi-functional Au@TS-1 catalysts were based on gold nanoparticles supported onto nanocrystalline titanium silicalite TS-1 which exhibited a double function, as inorganic matrix and epoxidation catalyst of olefins. The modification with metallic promoters, such as palladium and gold species was also considered to improve the catalytic activity of the solids (PdAu@TS-1). In this sense, several materials consisting on PdAu nanoparticles were prepared in order to study the dependence of their physico-chemical characteristics on the catalytic activity [40].

The preparation of TS-1 nanocrystals was carried out by combination of micellar and hydrothermal routes in presence of surfactants which facilitated the formation of small titanium silicalite crystallites during the synthesis process [39]. XRD diffractograms clearly evidenced that the as-synthesized and calcined phases, removing organic structural directing agents, corresponded to crystalline TS-1 zeolite, showing the characteristic diffraction bands of MFI-type materials (Figure 1). The alkaline media present in the synthesis gel favored the formation of charged small nuclei which were probably surrounded by surfactant molecules, avoiding crystal growth. In fact, TS-1 nanocrystals with $\sim 600 \mathrm{~nm}$ of size and containing very elevated titanium content ( $\mathrm{Si} / \mathrm{Ti}=35, \sim 2.0 \% \mathrm{wt}$ ) were obtained (Table 1). In these samples, at least most of the titanium was tetrahedrally coordinated into the zeolitic framework, this fact being important because it was reported that when high amounts of titanium are incorporated, significant octahedral extra-framework titanium was obtained, which is not active for epoxidation processes [45, 46]. UV-vis spectra and SEM micrographs confirmed the coordination state of the titanium and the size distribution of the TS-1 crystals respectively, as shown in Figure 2. The textural properties obtained from nitrogen adsorption showed that the nanocrystalline TS-1 was microporous, exhibiting type I plate isotherm characteristic of conventional 3D microporous zeolites (Figure 3 and Table 1).

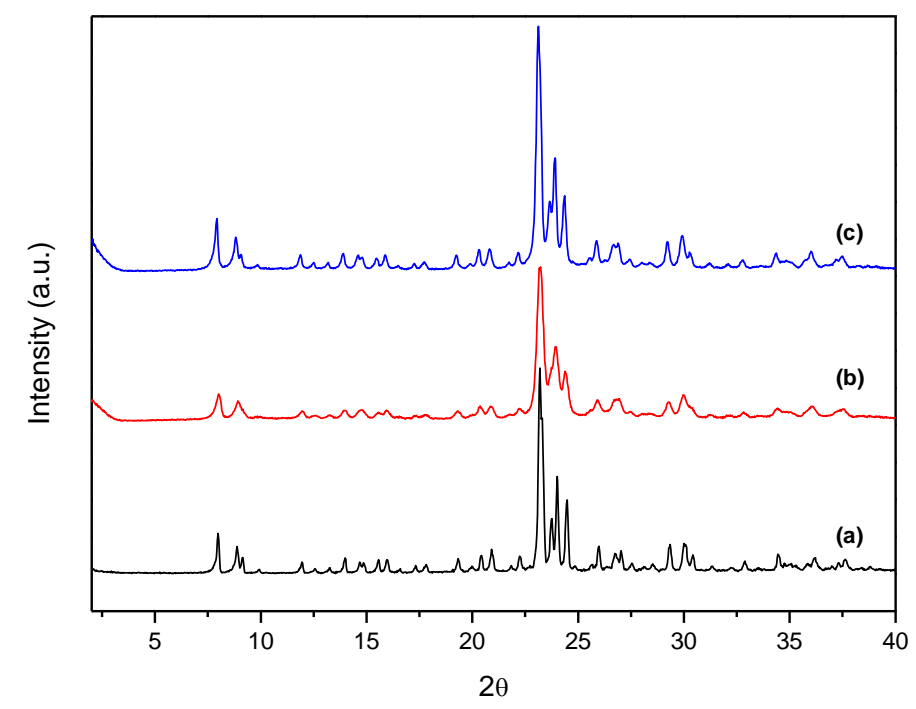

Figure 1. XRD patterns of (a) purely siliceous MFI-type zeolite, (b) as-synthesized TS-1 and (c) calcined TS-1. 
Table 1. Chemical analyses and textural properties of Pd(Au)@TS-1 samples.

\begin{tabular}{cccccccc} 
Samples $^{\mathbf{a}}$ & $\begin{array}{c}\mathrm{Ti} \\
(\% \mathbf{w t})\end{array}$ & $\begin{array}{c}\mathbf{A u} \\
(\% \mathbf{w t})\end{array}$ & $\begin{array}{c}\mathbf{P d} \\
(\% \mathbf{w t})\end{array}$ & $\begin{array}{c}\mathbf{S}_{\text {BET }} \\
\left(\mathbf{m}^{\mathbf{2}} \mathbf{g}^{-\mathbf{1}}\right)\end{array}$ & $\begin{array}{c}\mathbf{S}_{\text {MICRO }} \mathbf{b}^{\mathbf{b}} \\
\left(\mathbf{m}^{\mathbf{2}} \mathbf{g}^{-\mathbf{1}}\right)\end{array}$ & $\begin{array}{c}\mathbf{V}_{\text {TOT }} \\
\left(\mathbf{c m}^{\mathbf{3}} \mathbf{g}^{-\mathbf{1}}\right)\end{array}$ & $\begin{array}{c}\mathbf{V}_{\text {MICRO }} \\
\left(\mathbf{c m}^{\mathbf{3}} \mathbf{g}^{-\mathbf{1}}\right)\end{array}$ \\
\hline TS-1 & 1.89 & - & - & 416 & 266 & 0.240 & 0.130 \\
Pd10 & 1.88 & - & 0.86 & 400 & 243 & 0.235 & 0.119 \\
Au10 & 1.86 & 0.96 & - & 407 & 255 & 0.235 & 0.175 \\
Pd01Au01 & 1.99 & 0.21 & 0.15 & 435 & 272 & 0.252 & 0.130 \\
Pd02Au02 & 1.92 & 0.18 & 0.21 & 412 & 257 & 0.239 & 0.125 \\
Pd05Au05 & 1.91 & 0.54 & 0.42 & 424 & 267 & 0.242 & 0.128 \\
Pd10Au10 & 1.90 & 1.41 & 0.97 & 398 & 245 & 0.231 & 0.120 \\
Pd20Au20 & - & - & - & 327 & 218 & 0.201 & 0.107 \\
Pd10Au01 & 1.89 & 0.12 & 0.83 & 408 & 258 & 0.246 & 0.123 \\
Pd10Au02 & 1.88 & 0.30 & 0.77 & 402 & 261 & 0.227 & 0.124 \\
Pd10Au05 & 1.74 & 0.48 & 0.76 & 402 & 252 & 0.228 & 0.120 \\
\hline
\end{tabular}

${ }^{a}$ Number after Pd and Au indicates the theoretical Pd and Au loading (0.2 \%wt, $0.4 \% w t, 0.5 \% w t, 1.0 \% w t$ and $2.0 \% \mathrm{wt}$ ). All samples were supported onto TS-1 zeolite. ${ }^{\mathrm{b}}$ From $t$-plots curves. ${ }^{\mathrm{c}}$ Chemical analysis was not performed because the sample Pd20Au20@TS-1 was not possible to be dispersed.

(a)

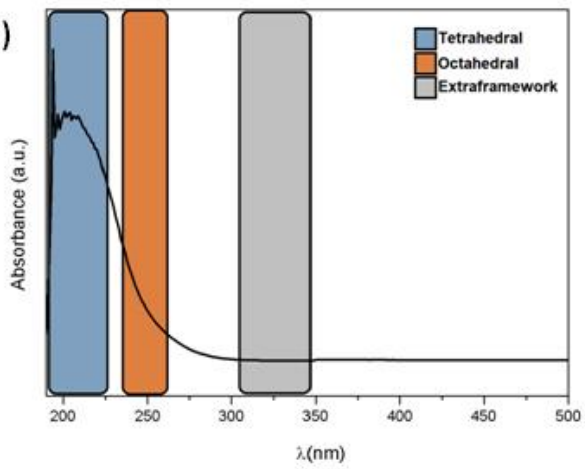

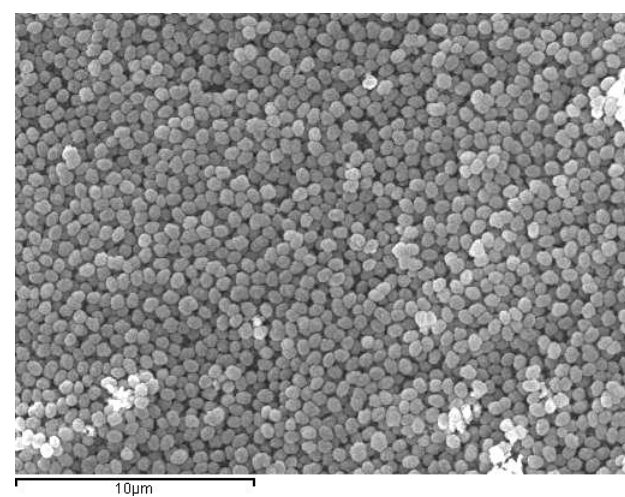

(b)

Figure 2. UV-Visible spectrum (a) and SEM micrographs (b) of calcined TS-1 obtained through combined hydrothermal and micellar routes.
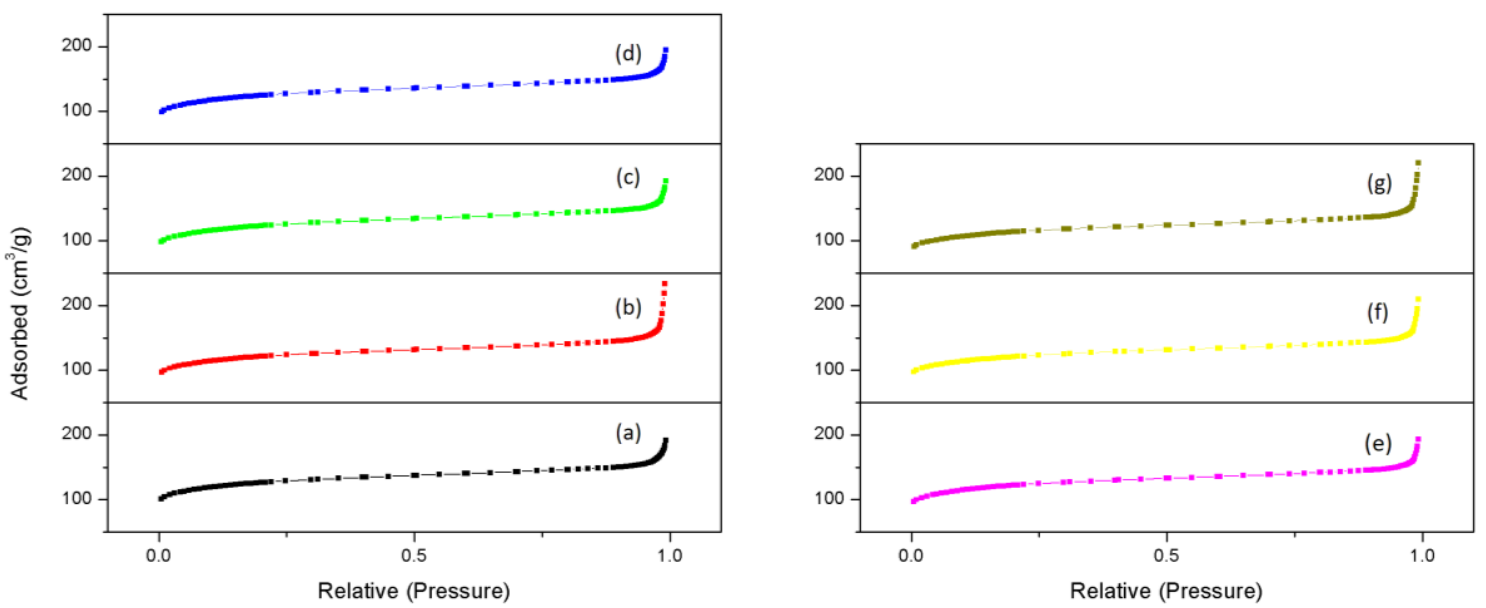

Figure 3. $\mathrm{N}_{2}$ isotherms of TS-1 and Pd(Au)@TS-1 samples: (a) TS-1, (b) Pd10@TS-1, (c) Au10@TS-1, (d) Pd02Au02@TS-1, (e) Pd05Au05@TS-1, (f) Pd10Au10@TS-1, (g)Pd20Au20@TS-1. 
Bi-functional Au@TS-1 materials were obtained through the deposition of gold species (from $0.2 \%$ to $2.0 \%$ in weight) by impregnation methodologies onto nanocrystalline TS-1 zeolite, used as supporting matrix. The incorporation of additional metallic promoters was similarly carried out, merging gold and palladium salts. Following this procedure, several Au@TS-1, Pd@TS-1 and PdAu@TS-1 materials were prepared with different loading of metallic species in function of metallic salts amount used during the impregnation process. The chemical content of the different samples prepared is shown in Table 1, being observed that the titanium content of TS-1 support ( $2 \% \mathrm{wt}$ ) was not modified by the presence of metallic species.

Furthermore, the crystallinity of the zeolitic phase remained unmodified after the palladium and/or gold deposition, such as it is confirmed by XRD patterns of the different samples which maintain the diffraction peaks characteristics of MFI-type zeolites without formation of silica amorphous phases (Figures 4 and 5). Interestingly, the peak corresponding to (111) metallic gold diffraction can be observed at $38.2^{\circ} 2 \theta$ in the case of the Au@TS-1 sample, as previously reported in literature [47]. However, the (111) diffraction peak of metallic palladium, in the case of the Pd@TS-1 sample, which commonly appears at $40.1^{\circ} 2 \theta$ [48], was not observed. Remarkably, the absence of this (111) diffraction peak from palladium was also confirmed in our previous studies [36], although the presence of palladium nanoparticles was confirmed through TEM and ICP analyses. This behavior has also been reported by Zhao et al. [49], who only observed the characteristic palladium (111) diffraction peak when samples with metallic contents greater than $6 \%$ were measured. Nevertheless, the presence of a broad signal in the PdAu samples was observed between the theoretical $2 \theta$ position of the (111) diffraction peaks of gold and palladium, specially at high metallic loadings, being this broad signal indicative of the presence of PdAu alloys as it was reported by Venezia et al. [50].
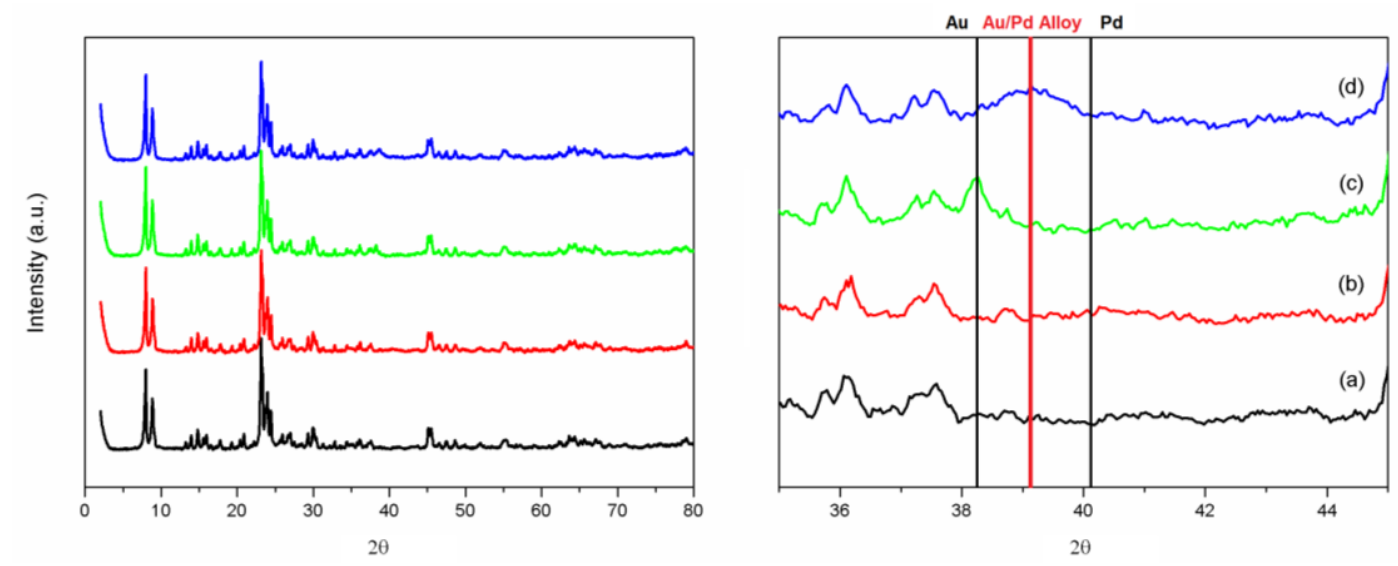

Figure 4. XRD of different samples: (a) TS-1, (b) Pd10@TS-1, (c) Au10@TS-1 and (d) Pd10Au10@TS-1 samples. 

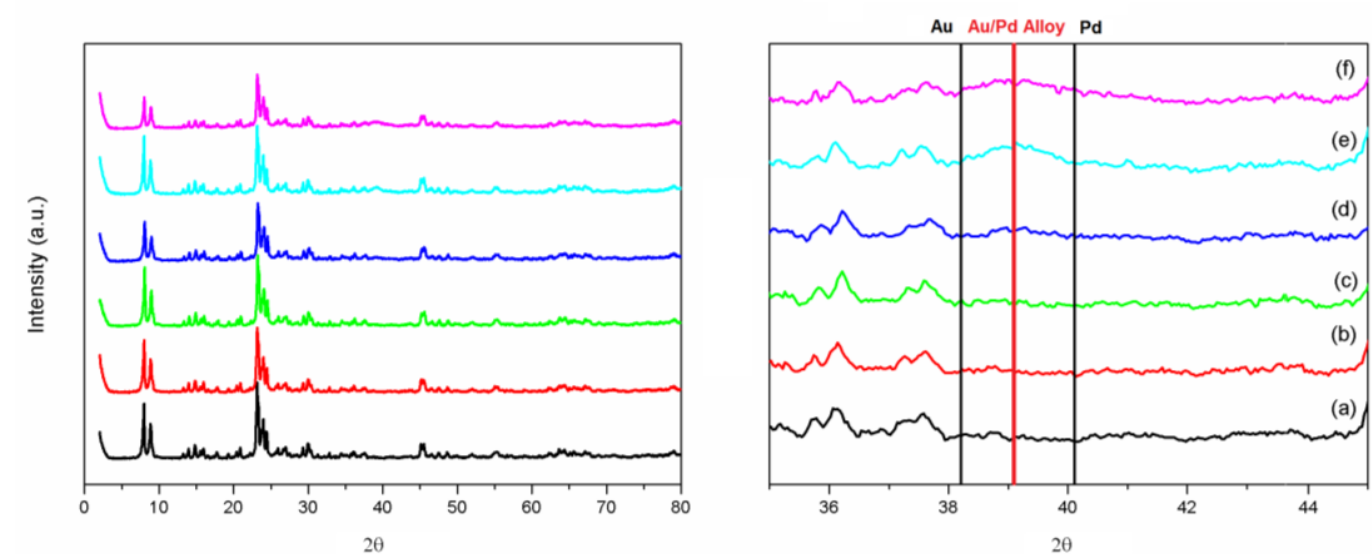

Figure 5. XRD of different samples: (a) TS-1, (b) Pd01Au01@TS-1, (c) Pd02Au02@TS-1, (d) Pd05Au05@TS-1, (e) Pd10Au10@TS-1 and (f) Pd20Au20@TS-1 samples.

On the other hand, it was confirmed that the followed deposition methodology to incorporate metallic species did not imply the generation of extra-framework titanium species. In this sense, UV-vis analysis showed not only the absence of extra-framework titanium species which are usually observed at $330 \mathrm{~nm}$ [51], but also an intense absorption band centered at $\sim 210 \mathrm{~nm}$ corresponding to charge transfer transition $\left[\mathrm{O}^{2-} \rightarrow \mathrm{Ti}^{+4}\right]$ of isolated tetrahedral titanium species present in the zeolitic framework (Figure 6) [52]. However, a shoulder in the absorption band in Pd10Au10@TS-1 sample was also observed, which may be indicative of the presence of small amounts of titanium in octahedral coordination at $\sim 230 \mathrm{~nm}$ on the samples with higher metallic content [53].

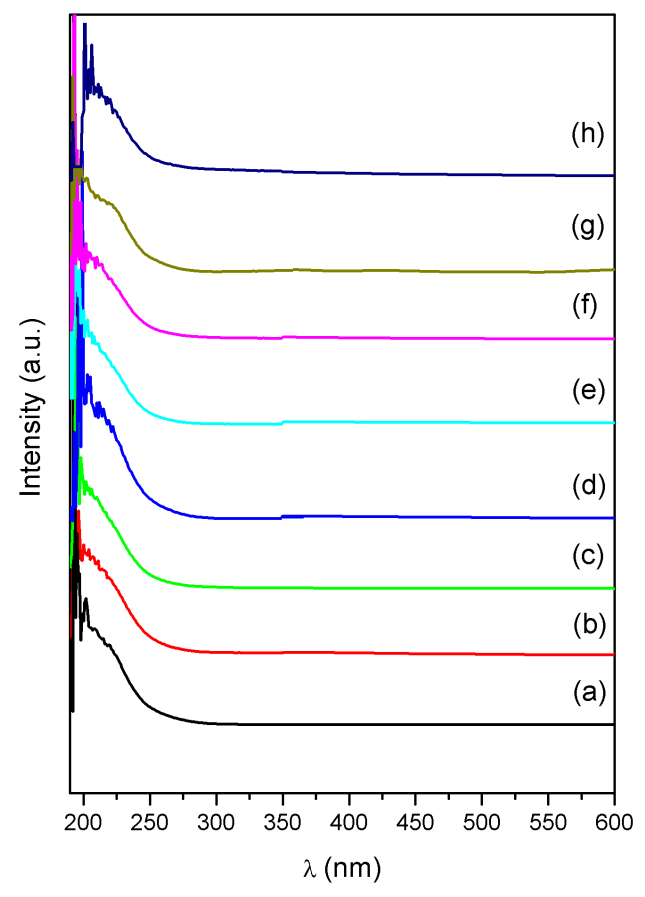

Figure 6. UV of PdAu@TS-1 samples: (a) TS-1, (b) Pd10@TS-1, (c) Au10@TS-1, (d) Pd01Au01@TS-1, (e) Pd02Au02@TS-1, (f) Pd05Au05@TS-1, (g) Pd10Au10@TS-1 and (h) Pd20Au20@TS-1 samples.

Moreover, a reduction in the total surface area and microporous volume was not detected in the samples with gold and/or palladium loadings lower than $1 \%$ wt. However, a decrease in the total surface area was detected in samples with higher loadings, especially in 
the Au20Pd20@TS-1 sample (Table 1), due to the partial blockage of the pores by the metallic nanoparticles. Nevertheless, nanoparticle deposition up to $2 \%$ wt did not lead to the complete blockage of the pores, exhibiting in all cases type I isotherms characteristic of microporous zeolitic materials (Figure 3).

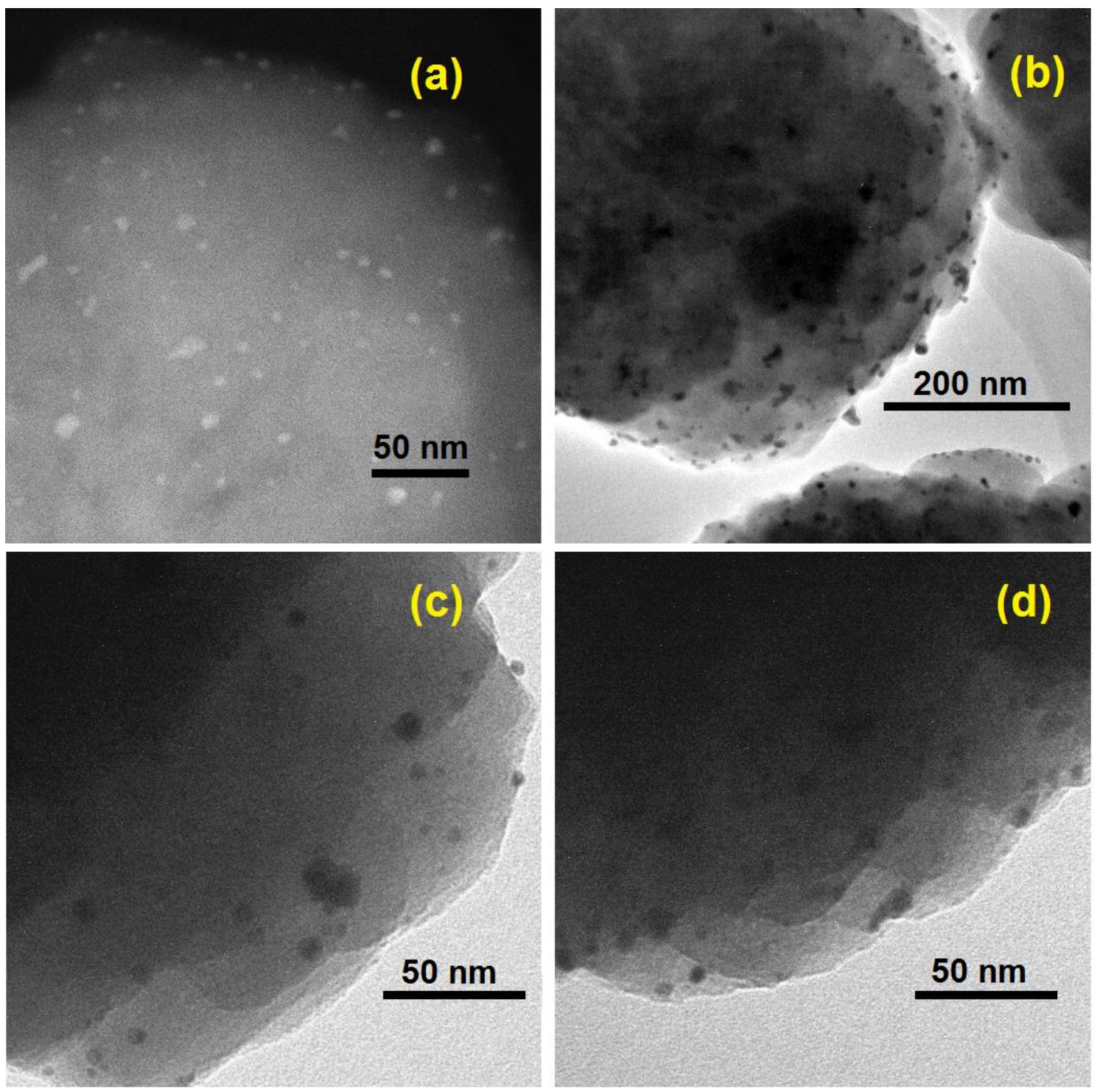



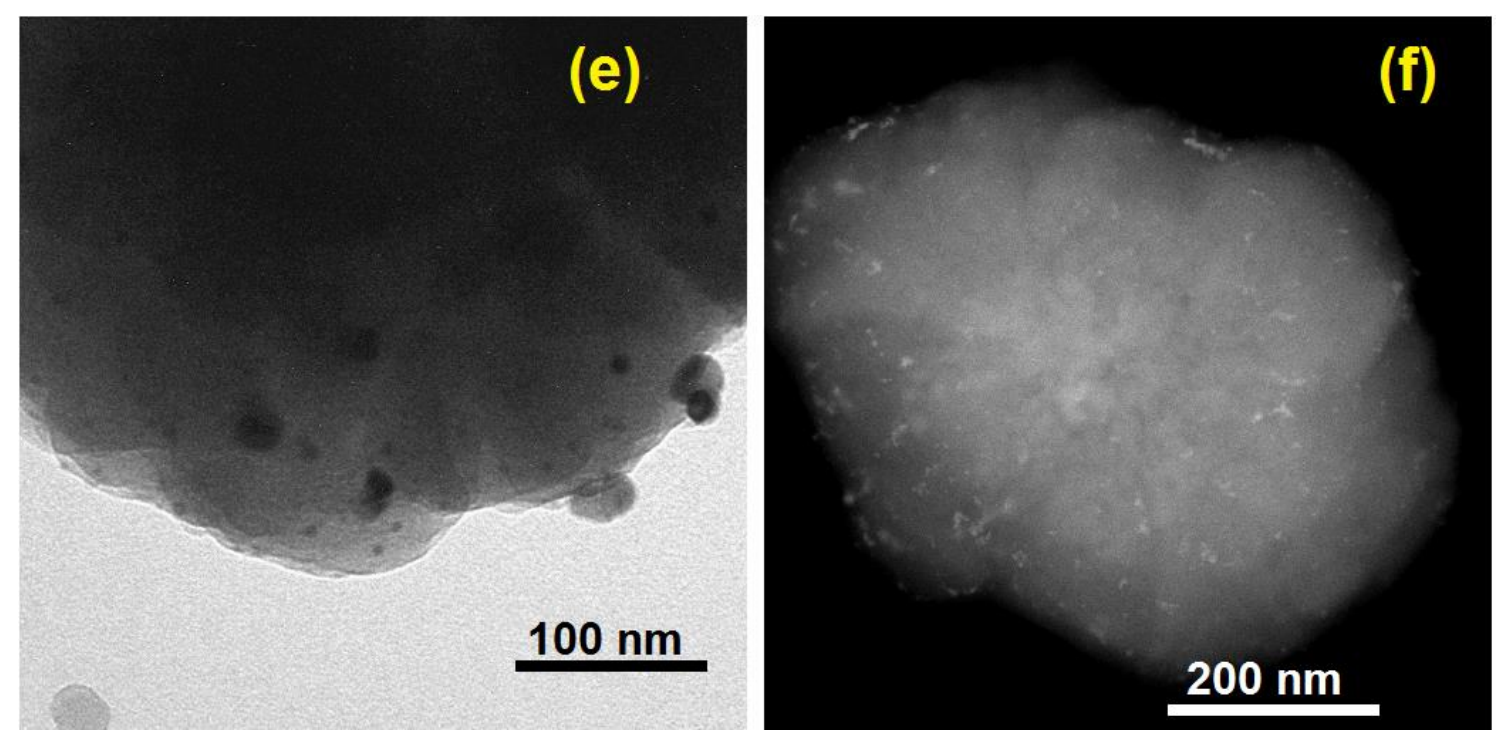

(a)
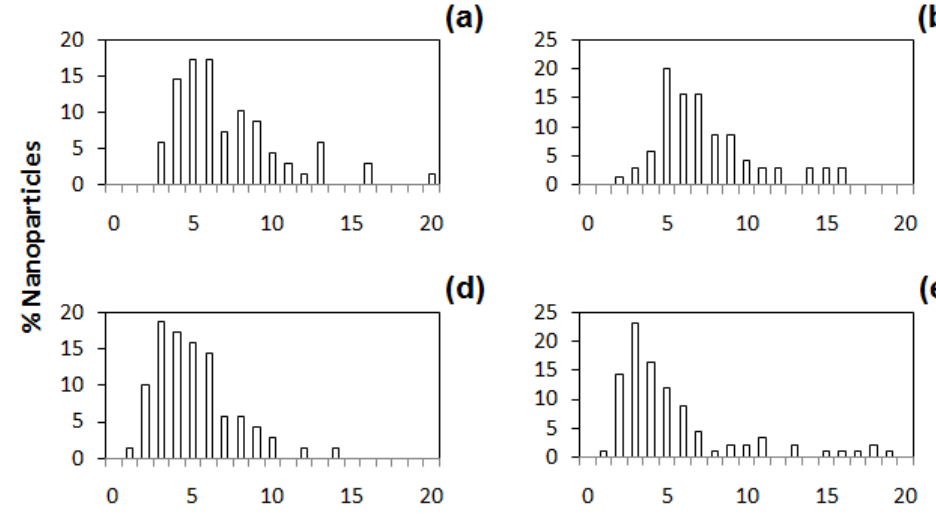

(b)

(c)

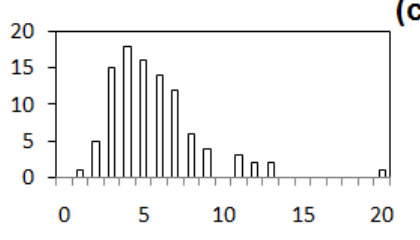

(e)

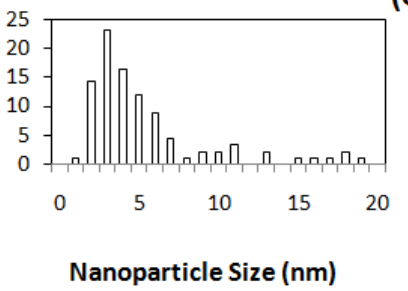

(f)

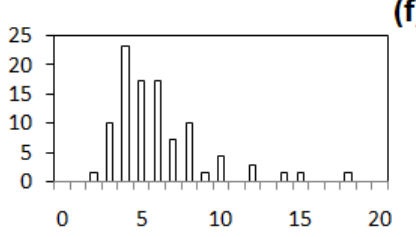

Figure 7. TEM micrographs and histograms of (a) Pd10@TS-1, (b) Au10@TS-1, (c) Pd10Au02@TS-1, (d) Pd10Au05@TS-1, (e) Pd05Au05@TS-1 and (f) Pd10Au10@TS-1 samples.

The TEM micrographs of different PdAu@TS-1 catalysts are shown in Figure 7, being observed that, regardless the metallic loading, most of the metallic nanoparticles exhibited sizes between 3-8 nm, although some nanoparticles larger than $20 \mathrm{~nm}$ were also measured (see histograms in Figure 7). This fact was also corroborated by previous studies where PdAu@TS-1 catalysts (2.5\% wt Pd and 2.5\% wt Au) containing PdAu nanoparticles of 130 nm were formed through similar methodologies [37]. However, although it is well-known that small nanoparticles are usually more active, it was confirmed that these catalysts with large nanoparticles were also able to generate $\mathrm{H}_{2} \mathrm{O}_{2}$, due to the high catalytic performance showed for these materials for $\mathrm{H}_{2} \mathrm{O}_{2}$ direct synthesis [37]. 


\section{Catalytic activity}

Preliminary batch catalytic tests, using nanocrystalline TS-1 zeolite as catalyst for the propylene epoxidation, in presence of external $\mathrm{H}_{2} \mathrm{O}_{2}$, were performed to produce PO. The results obtained clearly confirmed the high reactivity of the titanium silicalite TS-1 zeolite support to catalyze the epoxidation of propylene and the high efficiency of the process to obtain elevated PO yields ( $\sim 80-85 \%$, with respect to the oxidizing agent) with high selectivity ( 95-98\%). This fact evidenced the validity of nanocrystalline TS-1 materials to be used as active supports to generate effective bi-functional catalysts after the incorporation of different metallic nanoparticles. Moreover, the hydrothermal stability of the nanocrystalline TS- 1 zeolite support was additionally studied through several catalytic runs carried out with the same sample, without regeneration. Specifically, in Figure 8, it was observed that the PO yield obtained after the first reuse was similar compared with the results led by the activated fresh TS-1 catalyst. During the consecutive reuses, it was observed that PO selectivity remained stable, although the catalytic activity at short times decreased. However, even if the activity slightly decreased, longer reaction times led to complete conversion of $\mathrm{H}_{2} \mathrm{O}_{2}$ in presence of propylene to produce PO. This behavior is related with the formation of coke [10], which partially blocks zeolitic channels and pores. Although the initial activity can be completely restored through calcination at $550^{\circ} \mathrm{C}$, it is important to consider that the aim of this work is the use of PdAu@TS-1 catalysts for PO direct synthesis from $\mathrm{H}_{2} \mathrm{O}_{2}$, and under this high temperature reactivation treatment, the metallic nanoparticles could suffer sintering phenomena, negatively affecting to their catalytic performance. This issue will be further discussed on the stability tests. Definitively, these results corroborated that the TS-1 zeolite, used as active supporting matrix in the following one-pot two-step reactions, was catalytically effective, stable and active after several catalytic runs, without observing a substantial activity loss.

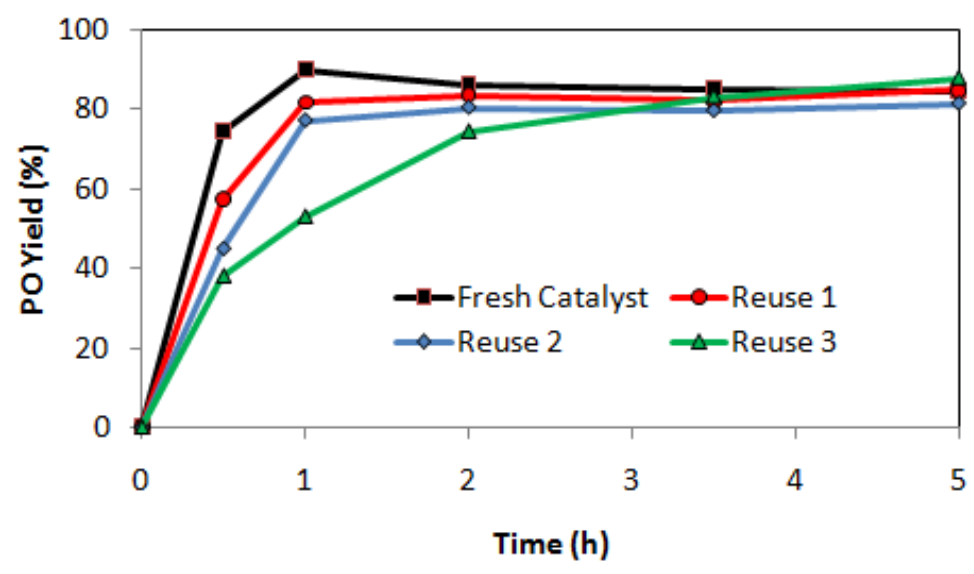

Figure 8. Catalytic activity and reuses of TS-1 zeolite support prepared by micellar route. The amount of the $\mathrm{H}_{2} \mathrm{O}_{2}$ was externally added according to the amount of the catalyst weight used in each reuse. On average, $\mathrm{R}_{\mathrm{H} 2 \mathrm{O} 2} / \mathrm{Ti}=120$. Propylene is added in excess, using $\mathrm{H}_{2} \mathrm{O}_{2}$ as limiting reactant. Reaction conditions: 14 bar of pressure, $60 \circ \mathrm{C}, 5 \mathrm{~h}$ reaction time. 
Considering these results, the next step was the catalytic study for the direct epoxidation of propylene with in-situ generated $\mathrm{H}_{2} \mathrm{O}_{2}$, during one-pot two-step reaction process. With this purpose, batch catalytic tests were carried out for the direct PO production from hydrogen, oxygen and propylene, using previously characterized bi-functional PdAu@TS1 nanocrystalline materials as catalysts. It is important to point out that when high yields to PO are obtained, also an increase in the amount of by-products formed during the reaction is observed, and high selectivities are only obtained at low propylene conversions, especially when gold is used as metal for the $\mathrm{H}_{2} \mathrm{O}_{2}$ synthesis from $\mathrm{H}_{2}$ and $\mathrm{O}_{2}$, in gaseous phase $[21,25]$.

Due to the high number of possible products that could be obtained in the reaction, it was decisive to find the most favorable reaction conditions, using bi-functional solid catalysts, for both the in situ generation of $\mathrm{H}_{2} \mathrm{O}_{2}$ and the consecutive epoxidation of propylene, in order to obtain high PO yield and selectivity, avoiding the by-products formation. Supercritical $\mathrm{CO}_{2}$ $\left(\mathrm{scCO}_{2}\right)$ has been claimed to be a good solvent for the direct production of $\mathrm{PO}$, enhancing also the $\mathrm{H}_{2} \mathrm{O}_{2}$ efficiency for the epoxidation reaction [34]. For this reason, in the first set of reactions, $\mathrm{CO}_{2}$ has been used as reaction medium together with several co-solvents in order to find out the optimal reaction conditions, taking the bi-functional Pd10Au10@TS-1 catalyst as reference.

Table 2. Catalytic tests carried out with in-situ generated $\mathrm{H}_{2} \mathrm{O}_{2}$ using supercritical $\mathrm{CO}_{2}$ conditions in presence of different catalysts. ${ }^{a}$

\begin{tabular}{|c|c|c|c|c|c|c|c|c|c|}
\hline Entry & $\begin{array}{c}\text { Catalyst } \\
\text { @TS-1 }\end{array}$ & Co-Solvent & $\mathrm{C}_{3}{ }^{=} / \mathrm{H}_{2} / \mathrm{O}_{2}{ }^{\mathrm{b}}$ & $X_{\mathrm{C} 3}{ }^{c}$ & $S_{P O}^{d}$ & $S_{M P}^{d}$ & $S_{P G}{ }^{d}$ & $\mathrm{~S}_{\mathrm{C} 3}{ }^{\mathrm{d}}$ & $\mathrm{Y}_{\mathrm{PO}} \mathrm{e}^{\mathrm{e}}$ \\
\hline 1 & Pd10Au10 & - & $1 / 0.9 / 0.9$ & 1.2 & - & - & - & $>99$ & - \\
\hline 2 & Pd10Au10 & $\mathrm{MeOH}$ & $1 / 1.2 / 0.8$ & 64.9 & 2.2 & 1.1 & - & 96.7 & 1.4 \\
\hline 3 & Pd10Au10 & $\mathrm{H}_{2} \mathrm{O}$ & 1/1.0/1.0 & 37.0 & 1.3 & - & 0.4 & 94.4 & 0.5 \\
\hline 4 & Pd10Au10 & $\mathrm{MeOH}+\mathrm{H}_{2} \mathrm{O}$ & $1 / 1.1 / 1.2$ & 52.4 & 1.5 & 4.9 & 0.5 & 93.1 & 0.8 \\
\hline 5 & Pd10Au10 & $\mathrm{MeOH}+\mathrm{H}_{2} \mathrm{O}+\mathrm{Al}^{f}$ & 1/1.2/1.3 & 17.9 & 57.8 & 3.0 & 1.3 & 37.9 & 10.3 \\
\hline 6 & Pd10Au10 & $\mathrm{H}_{2} \mathrm{O}+\mathrm{Al}$ & $1 / 0.8 / 1.3$ & 15.9 & 33.0 & - & 1.2 & 63.4 & 5.2 \\
\hline 7 & Pd10Au10 & $\mathrm{MeOH}+\mathrm{Al}$ & $1 / 1.0 / 1.0$ & 15.8 & 75.5 & 2.8 & 1.1 & 16.3 & 11.9 \\
\hline 8 & Pd10Au10 & $\mathrm{MeOH}+\mathrm{Al}+\mathrm{NaBr}$ & 1/0.9/1.0 & 12.9 & 83.4 & 2.7 & 0.3 & 13.5 & 10.8 \\
\hline 9 & Pd10 & $\mathrm{MeOH}+\mathrm{Al}$ & $1 / 1.2 / 1.2$ & 11.5 & 75.0 & 3.9 & 1.1 & 19.9 & 8.6 \\
\hline 10 & Au10 & $\mathrm{MeOH}+\mathrm{Al}$ & 1/1.0/1.0 & 2.6 & 9.0 & - & - & 91.0 & 0.2 \\
\hline 11 & Pd10 & $\mathrm{MeOH}$ & 1/1.1/1.0 & 36.9 & 25.9 & 8.6 & 0.6 & 64.9 & 9.5 \\
\hline 12 & Au10 & $\mathrm{MeOH}$ & 1/1.2/1.1 & 29.0 & 1.7 & 1.3 & - & 97.0 & 0.5 \\
\hline
\end{tabular}

${ }^{\mathrm{a}}$ Reactions were carried out for $5 \mathrm{~h}$ with pressures around 75 bar and $60^{\circ} \mathrm{C}$, feeding $2 \mathrm{mmol}$ of propylene and $15 \mathrm{mg}$ catalyst. ${ }^{b}$ Gaseous molar ratios. ${ }^{c}$ Propylene conversion. ${ }^{d}$ Propylene oxide, methyl propanols, propylene glycol and propane selectivity. ${ }^{e}$ Propylene oxide yield. ${ }^{\mathrm{f}}$ Acidity Inhibitor $\left(\mathrm{CH}_{3} \mathrm{COONH}_{4}\right)$. Conversion, selectivity and yield values are given in \%.

The catalytic results showed that the bi-functional Pd10Au10@TS-1 catalyst was not able to produce PO from in-situ generated $\mathrm{H}_{2} \mathrm{O}_{2}$ from $\mathrm{H}_{2}$ and $\mathrm{O}_{2}$ using $\mathrm{CO}_{2}$ as sole solvent (Table 2, entry 1 ), the only detected product being propane. 
In that sense, it is nowadays accepted that the formation of metal peroxo compounds ( $\mathrm{Ti}-\mathrm{OOH}$ ) through the reaction between $\mathrm{Ti}$ and $\mathrm{H}_{2} \mathrm{O}_{2}$ is a key intermediate step on the epoxidation reaction with TS-1 catalysts. Bellusi et al. [54] reported that $\mathrm{Ti}-\mathrm{OOH}$ species have a five-membered cyclic structure with a donor hydroxyl moiety coordinated to titanium which reacts with propylene to yield propylene oxide (Figure 9).
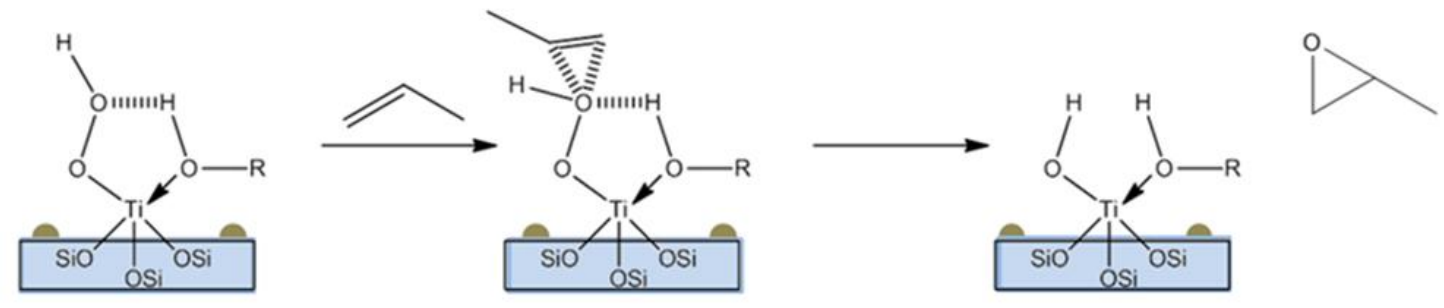

Figure 9. Mechanism for the formation of five-membered cyclic structure over TS-1 catalyst and its reaction with propylene to yield propylene oxide.

Following this approach, donor hydroxyl groups might come from the solvent, being obtained the best results on the propylene epoxidation reaction in presence of $\mathrm{H}_{2} \mathrm{O}_{2}$ as oxidizing agent and methanol as solvent, which efficiently helped to obtain the five-membered cyclic structure. Moreover, not only methanol, but also others protic solvents such as ethanol, $t$-butanol or even water, are able to help in the formation of these intermediate species.

Taking this into account, we also considered the incorporation of additional cosolvents. The results obtained showed that the use of methanol, water or a mixture of both solvents result in an improvement of the propylene oxide selectivity, but propane was the main reaction product in all experiments (Table 2, entries 2-4). These results are consistent with previous study of Hölderich et al. who already pointed out that the co-deposition of gold together with palladium lead not only to worse PO yields compared with bare palladium catalysts, but also to higher propane selectivity [38].

However, it has already been proved [35] that the hydrogenation product selectivity using PdPt based catalysts can be effectively reduced in presence of acidity inhibitors, enhancing PO selectivity. The reason for this behavior remains unclear, although the positive effect of alkalis or $\mathrm{NH}_{4} \mathrm{NO}_{3}$ on $\mathrm{PO}$ productivity and selectivity, using Au based bifunctional catalysts, has been previously reported $[55,56]$, being effectively suppressed propylene hydrogenation over gold clusters [57, 58]. According to this, the higher activity could be related with two main reasons: i) the formation of $\mathrm{Au}$-amine complexes which are more active than single Au species for $\mathrm{H}_{2} \mathrm{O}_{2}$ synthesis and ii) the more efficient removal of residual $\mathrm{Cl}^{-}$ions (from the precursor $\mathrm{HAuCl}_{4}$ ) by the $\mathrm{NH}_{4}{ }^{+}$species. In that sense, it is important to consider that chlorine is a poisoning agent for Au catalysts, due to the formation of $\mathrm{Au}-\mathrm{Cl}$ species, and should be removed efficiently after the catalyst preparation. Taking this account, we have also tested the effect of ammonium acetate in presence of water, methanol and mixtures of these solvents in order to find out the best reaction medium (Table 2, entries 5-7). Best results were achieved when methanol and ammonium acetate were used in absence of water, leading to PO selectivities up to $75.5 \%$ and conversions of $15.8 \%$ (Table 2, entry 7). Moreover, the use of ammonium acetate seems to have not only an effect in the propane formation, but also in the 
reduction of non-desired ring-opening reactions, leading to an improvement of the propylene oxide selectivity. In this sense, it has already been published that the pre-treatment of TS-1 with different salts, such as sodium acetate and ammonium acetate among others, neutralizes the weak acid Si-OH groups of the catalyst, avoiding non desired ring-opening reactions [10, 59].

Furthermore, these tests also showed that the use of water as co-solvent substantially worsened the catalytic results, both in absence and in the presence of ammonium acetate (Table 2, entries 3 and 6). As we previously discussed, water can also help in the formation of the five-membered cyclic structure, promoting PO formation, but methanol is the most preferred solvent for the formation of such intermediate. For this main reason, the results obtained in the presence of water are not as good as the ones obtained with methanol.

Besides, it is well-known $[60,61,62]$ that halide ions have a beneficial effect in the oxidation of $\mathrm{H}_{2}$ to $\mathrm{H}_{2} \mathrm{O}_{2}$ over Pd-based catalysts, due to its inhibitor effect in the water formation reaction, increasing $\mathrm{H}_{2} \mathrm{O}_{2}$ selectivity. For this, the reaction was also tested in the presence of ammonium acetate and sodium bromide, seeking to reduce both the $\mathrm{H}_{2} \mathrm{O}_{2}$ degradation to water and the formation of propane. The results showed an improvement in propylene oxide selectivity (83.4\%), with a slightly lower propylene conversion (Table 2, entry 8).

On the other hand, the effect of the addition of gold as promoter was also analyzed (Table 2, entries 9 and 10). The results showed the bare Pd10@TS-1 catalyst exhibited a lower catalytic performance than Pd10Au10@TS-1 catalyst when the same reaction conditions were used (Table 2, entries 7 and 9). Interestingly, the use of bare Au10@TS-1 catalyst led to very low catalytic activity, being propane the main reaction product, showing the beneficial effect of gold and palladium metallic species coexisting in the same solid catalyst. In this sense, the results were consistent with those previously reported by Moreno et al. [37] who also observed that bare Au nanoparticles deposited over TS-1 were not able to produce any $\mathrm{H}_{2} \mathrm{O}_{2}$, meanwhile bare $\mathrm{Pd}$ nanoparticles and especially $\mathrm{Au}-\mathrm{Pd}$ alloy nanoparticles deposited over TS-1 were indeed able to produce $\mathrm{H}_{2} \mathrm{O}_{2}$ when $\mathrm{H}_{2}$ and $\mathrm{O}_{2}$ are fed in a $\mathrm{CO}_{2}$ atmosphere. These experimental results clearly suggest a synergetic effect between palladium and gold. This behaviour has also been observed in $\mathrm{H}_{2} \mathrm{O}_{2}$ direct synthesis $[63,64]$ and the reason remains still as matter of study. However, the role of gold seems to be mainly the modification of the characteristics of palladium, acting as an activity promoter. The enhanced activity could be related with two main reasons: i) $\mathrm{Pd} / \mathrm{Au}$ alloys are more active and its structure is more stable than bare palladium [65] or ii) gold inhibits the $\mathrm{O}_{2}$ dissociation on palladium, reducing the water formation reaction and enhancing the selectivity towards $\mathrm{H}_{2} \mathrm{O}_{2}$ [66]. So, the synergetic effect between palladium and gold leads to a higher $\mathrm{H}_{2} \mathrm{O}_{2}$ production efficiency, resulting in a higher PO production.

Interestingly, the results here obtained using methanol as co-solvent in the absence of the acidity inhibitor (Table 2, entry 2) showed that the presence of methoxypropanols is barely observed, being propane the main product. In order to elucidate the reason for this behavior, the reaction was also tested in presence of Pd10@TS-1 and Au10@TS-1 catalysts without acidity inhibitor. The results (Table 2, entries 11 and 12) showed that, meanwhile Pd10@TS-1 catalyst led to higher amounts of methoxypropanols and lower of propane than 
Pd10Au10@TS-1 catalyst (Table 2, entry 2), the Au10@TS-1 catalyst leads mainly to propane, being methoxypropanols barely observed. These results clearly show that the formation of propane is strongly favored by the presence of single gold nanoparticles on the solid catalyst, being important that gold is present together with palladium in order to obtain satisfactory catalytic results.

Besides, it is well-known that $\mathrm{H}_{2} \mathrm{O}_{2}$ synthesis in batch conditions is promoted when low reaction temperatures, close to $0 \circ \mathrm{C}$, are used, meanwhile propylene epoxidation in batch conditions is normally promoted at higher temperatures, in the range of $40-60$ ㅇ $C[10,67,68]$. However, gold catalysts have shown their best catalytic performance for propylene epoxidation in gaseous phase with in-situ generated $\mathrm{H}_{2} \mathrm{O}_{2}$ at higher temperatures, up to $200 \circ \mathrm{C}$ $[22,25,69]$, and even at $300^{\circ} \mathrm{C}[70,71]$. Taking into account the high catalytic activity of gold species in gaseous phase at high temperatures, it was important to study the effect of gold on the most preferred reaction temperature in batch conditions. The results obtained showed a slight decrease on selectivity when reaction is carried out at $70 \circ \mathrm{C}$, and the increase from $70 \circ \mathrm{C}$ to $80 \circ \mathrm{C}$ resulted in a sharp decrease on selectivity, being observed the presence of higher amounts of ring-opening products. The results presented on Table 3 proved that $60 \circ \mathrm{C}$ was the optimal reaction temperature to carry out the one-pot two-step process under our reaction conditions, even in presence of gold nanoparticles as catalytic promoters.

Table 3. Catalytic tests carried out with in-situ generated $\mathrm{H}_{2} \mathrm{O}_{2}$ using supercritical $\mathrm{CO}_{2}$ conditions in presence of Pd10Au10@TS-1 catalyst at different temperatures. ${ }^{2}$

\begin{tabular}{ccccccccc} 
Entry & Temperature & $\mathrm{C}_{3}{ }^{3} / \mathrm{H}_{2} / \mathbf{O}_{2}{ }^{\mathrm{c}}$ & $\mathbf{X}_{\mathrm{C} 3=}{ }^{\mathrm{d}}$ & $\mathbf{S}_{\mathrm{PO}}{ }^{\mathrm{e}}$ & $\mathbf{S}_{\mathrm{MP}}{ }^{\mathrm{e}}$ & $\mathbf{S}_{\mathrm{PG}}{ }^{\mathrm{e}}$ & $\mathbf{S}_{\mathrm{C} 3}{ }^{\mathrm{e}}$ & $\mathbf{Y}_{\mathrm{PO}}{ }^{\mathrm{f}}$ \\
\hline 1 & $\mathrm{RT}^{\mathrm{b}}$ & $1 / 0.9 / 1.0$ & 4.0 & 77.1 & 1.5 & - & 18.9 & 3.1 \\
2 & 40 & $1 / 0.9 / 1.0$ & 9.3 & 77.5 & 0.7 & 0.4 & 14.4 & 7.2 \\
3 & 50 & $1 / 1.0 / 1.1$ & 10.7 & 69.2 & 1.8 & 1.3 & 23.5 & 7.4 \\
4 & 60 & $1 / 1.0 / 1.0$ & 15.8 & 75.5 & 2.8 & 1.1 & 16.3 & 11.9 \\
5 & 70 & $1 / 0.9 / 1.1$ & 16.9 & 70.5 & 12.3 & 2.2 & 8.1 & 11.9 \\
6 & 80 & $1 / 1.2 / 1.0$ & 20.1 & 45.2 & 26.2 & 10.8 & 14.3 & 9.1
\end{tabular}

${ }^{a}$ Reactions were carried out for $5 \mathrm{~h}$ at different reaction temperatures with pressures around 75 bar, feeding 2 $\mathrm{mmol}$ of propylene and $15 \mathrm{mg}$ catalyst. ${ }^{\mathrm{b}}$ Room temperature $(\mathrm{o})$. ${ }^{\mathrm{c}}$ Gaseous molar ratios. ${ }^{\mathrm{d}}$ Propylene conversion. ${ }^{\mathrm{e}}$ Propylene oxide, methyl propanols, propylene glycol and propane selectivities. ${ }^{f}$ Propylene oxide yield. Conversion, selectivity and yield values are given in $\%$.

On the other hand, metallic nanoparticles are not only able to generate $\mathrm{H}_{2} \mathrm{O}_{2}$, but also can decompose $\mathrm{H}_{2} \mathrm{O}_{2}$ to form water, catalyzing the propylene hydrogenation. Besides, metallic nanoparticles can also lead to the blockage of the zeolitic pores, favoring diffusion problems and decreasing the catalytic performance. For this reason, the amount of metals deposited onto the TS- 1 support was studied, in order to obtain as much $\mathrm{H}_{2} \mathrm{O}_{2}$ as possible, at the same time that selectivity to $\mathrm{PO}$ remained high. Moreover, considering that the presence of gold had a beneficial effect in our catalytic system, although could favor the hydrogenation reaction, the most favorable $\mathrm{Pd} / \mathrm{Au}$ ratios in our catalysts were also investigated. Thus, several bi-functional catalysts with different $\mathrm{Au}$ and $\mathrm{Pd}$ loadings $(0.2 \%, 0.5 \%, 1.0 \%$ and $2.0 \%$ in weight) and different $\mathrm{Pd} / \mathrm{Au}$ ratios $\left(\mathrm{R}_{\mathrm{Pd} / \mathrm{Au}}=1,2,5,10\right)$ were compared (Table 4). 
Table 4. Catalytic tests carried out with in-situ generated $\mathrm{H}_{2} \mathrm{O}_{2}$ using supercritical $\mathrm{CO}_{2}$ conditions in presence of different $\mathrm{Pd}(\mathrm{Au}) @ \mathrm{TS}-1$ catalysts. ${ }^{\mathrm{a}}$

\begin{tabular}{|c|c|c|c|c|c|c|c|c|c|}
\hline Entry & $\begin{array}{c}\text { Catalyst } \\
\text { @TS-1 }\end{array}$ & Co-Solvent & $\mathrm{C}_{3}{ }{ } / \mathrm{H}_{2} / \mathrm{O}_{2}{ }^{\mathrm{b}}$ & $\mathrm{X}_{\mathrm{C} 33}{ }^{\mathrm{c}}$ & $S_{P O}{ }^{d}$ & $S_{M P}^{d}$ & $S_{P G}^{d}$ & $\mathrm{~S}_{\mathrm{C} 3}{ }^{\mathrm{d}}$ & $Y_{P O}^{e}$ \\
\hline 1 & $\mathrm{Pd02Au02}$ & $\mathrm{MeOH}+\mathrm{Al}^{f}$ & $1 / 1.1 / 1.1$ & 12.1 & 77.9 & 3.3 & 1.7 & 15.2 & 9.4 \\
\hline 2 & Pd05Au05 & $\mathrm{MeOH}+\mathrm{Al}$ & 1/1.0/1.1 & 12.3 & 77.6 & 7.3 & 2.1 & 13.0 & 9.5 \\
\hline 3 & Pd10Au10 & $\mathrm{MeOH}+\mathrm{Al}$ & 1/1.0/1.0 & 15.8 & 75.5 & 2.8 & 1.1 & 16.3 & 11.9 \\
\hline 4 & Pd20Au20 & $\mathrm{MeOH}+\mathrm{Al}$ & $1 / 1.0 / 1.0$ & 10.2 & 71.3 & 1.3 & 0.1 & 25.3 & 7.3 \\
\hline 5 & Pd10Au01 & $\mathrm{MeOH}+\mathrm{Al}$ & 1/0.9/1.1 & 12.9 & 69.7 & 5.1 & 3.4 & 16.6 & 9.0 \\
\hline 6 & Pd10Au02 & $\mathrm{MeOH}+\mathrm{Al}$ & 1/1.0/1.1 & 15.6 & 82.9 & 2.8 & 1.5 & 12.2 & 12.9 \\
\hline 7 & Pd10Au05 & $\mathrm{MeOH}+\mathrm{Al}$ & 1/0.9/1.1 & 18.2 & 57.1 & 2.4 & 1.3 & 38.1 & 10.4 \\
\hline
\end{tabular}

${ }^{\mathrm{a}}$ Reactions were carried out for $5 \mathrm{~h}$ with pressures around 75 bar and $60^{\circ} \mathrm{C}$, feeding $2 \mathrm{mmol}$ of propylene and $15 \mathrm{mg}$ catalyst. ${ }^{b}$ Gaseous molar ratios. ${ }^{c}$ Propylene conversion. ${ }^{d}$ Propylene oxide, methyl propanols, propylene glycol and propane selectivity. ${ }^{e}$ Propylene oxide yield. ${ }^{f}$ Acidity Inhibitor $\left(\mathrm{CH}_{3} \mathrm{COONH}_{4}\right)$. Conversion, selectivity and yield values are given in \%.

In the first place, we studied the activity of materials with similar loading of $\mathrm{Pd}$ and $\mathrm{Au}$ (Table 4, Entries 1-4), observing that the best catalytic result was obtained with Pd10Au10 catalyst. It is important to point out that, in general, the propane selectivity increased with the metallic loading, meanwhile the selectivity to PO and ring-opening products decreased, owing to the ability of the metallic nanoparticles to carry out hydrogenation reactions. This behavior can be attributed mainly to two reasons: i) higher hydrogenation capacity at higher metallic loadings and ii) pore and channels partial blocking due to the deposition of increasing amounts of metallic nanoparticles, which led to diffusional problems.

With regard to the metallic ratio (Table 4, Entries 5-7), we observed that best results were obtained with Pd10Au02 catalyst, with a $\mathrm{Pd} / \mathrm{Au}$ ratio 5, which yielded $12.9 \% \mathrm{PO}$, with a selectivity of $82.9 \%$, being observed an increase of propane production when gold ratio was increased. In this way, although it is clear that the presence of gold effectively enhances the bifunctional catalyst performance, gold amount has to be controlled, due to its high activity for the propylene hydrogenation in presence of methanol as co-solvent [38].

On the other hand, the most adequate reaction time for the propylene oxide production was also evaluated. Considering the previous results, reaction was carried out using Pd10Au02 catalyst and in presence of methanol together with small amounts of ammonium acetate as buffer from 1 to 12 hours at $60^{\circ} \mathrm{C}$. 
Table 5. Catalytic tests carried out with in-situ generated $\mathrm{H}_{2} \mathrm{O}_{2}$ using supercritical $\mathrm{CO}_{2}$ conditions in presence of different Pd10Au02@TS-1 catalysts at different reaction times. ${ }^{a}$

\begin{tabular}{|c|c|c|c|c|c|c|c|c|c|c|}
\hline Entry & Time (h) & $\mathrm{C}_{3}{ }^{=} / \mathrm{H}_{2} / \mathrm{O}_{2}{ }^{\mathrm{b}}$ & $\mathbf{X}_{\mathrm{C} 3}{ }^{\mathrm{c}}$ & $\mathrm{SPO}^{\mathrm{d}}$ & $S_{M P}^{d}$ & $S_{P G}{ }^{d}$ & $\mathrm{~S}_{\mathrm{C} 3}{ }^{d}$ & $\mathrm{Y}_{\mathrm{PO}}{ }^{\mathrm{e}}$ & TOF $^{f}$ & $\mathrm{PRO}^{\mathrm{g}}$ \\
\hline 1 & 1 & $1 / 0.8 / 1.0$ & 2.9 & 72.5 & 0.8 & - & 20.9 & 2.1 & 6.3 & 52 \\
\hline 2 & 3 & $1 / 0.9 / 1$ & 10.9 & 83.7 & 1.8 & 1.2 & 13.3 & 9.1 & 27.8 & 228 \\
\hline 3 & 5 & 1/1.0/1.1 & 15.6 & 82.9 & 2.8 & 1.5 & 12.2 & 12.9 & 39.5 & 323 \\
\hline 4 & 7 & $1 / 1.0 / 1.0$ & 21.2 & 83.1 & 6.3 & 3.3 & 7.3 & 17.6 & 49.8 & 407 \\
\hline 5 & 12 & $1 / 1.0 / 1.0$ & 26.1 & 45.4 & 24.2 & 7.5 & 22.9 & 11.8 & 35.1 & 287 \\
\hline
\end{tabular}

${ }^{a}$ Reactions were carried out at different reaction times with pressures around 75 bar and $60 \circ \mathrm{C}$, feeding $2 \mathrm{mmol}$ of propylene and $15 \mathrm{mg}$ catalyst. ${ }^{\mathrm{b}}$ Gaseous molar ratios. ${ }^{\mathrm{C}}$ Propylene conversion. ${ }^{\mathrm{d}}$ Propylene oxide, methyl propanols, propylene glycol and propane selectivities. ${ }^{e}$ Propylene oxide yield. ${ }^{f}$ Turnover frequency $\left(\mathrm{h}^{-1}\right) .{ }^{\mathrm{g}}$ Productivity (mol ${ }_{\mathrm{PO}}$ $\left.\mathrm{kg}_{\text {cat }}{ }^{-1} \mathrm{~h}^{-1}\right)$. Conversion, selectivity and yield values are given in \%.

The results showed that higher propylene conversion and propylene oxide selectivity were obtained when reaction time was increased, being observed a strong decrease on propylene oxide selectivity after $12 \mathrm{~h}$. This behavior could be explained both by the formation of ring-opening products at longer times and by the deactivation of PdAu species, which are highly active for $\mathrm{H}_{2} \mathrm{O}_{2}$ production during short times [72], producing only water afterwards. This last behavior has been assigned to the $\mathrm{Pd}$ oxidation during the reaction process [73] favored by the $\mathrm{H}_{2} \mathrm{O}_{2}$ formed, leading to a decrease not only in the catalytic activity but also in the selectivity of the Pd nanoparticles.

Finally, the stability of the bi-functional Pd(Au)@TS-1 catalysts was evaluated through several consecutive catalytic cycles. After each reuse, the catalyst solid was recovered, exhaustively washed with methanol, dried at $100 \circ \mathrm{C}$ overnight and reduced in presence of hydrogen at room temperature during $3 \mathrm{~h}$. After the $2^{\text {nd }}$ reuse, the catalyst was regenerated through a temperature treatment at $200 \circ \mathrm{C}$ followed by reduction with $\mathrm{H}_{2}$, as detailed on the experimental part.

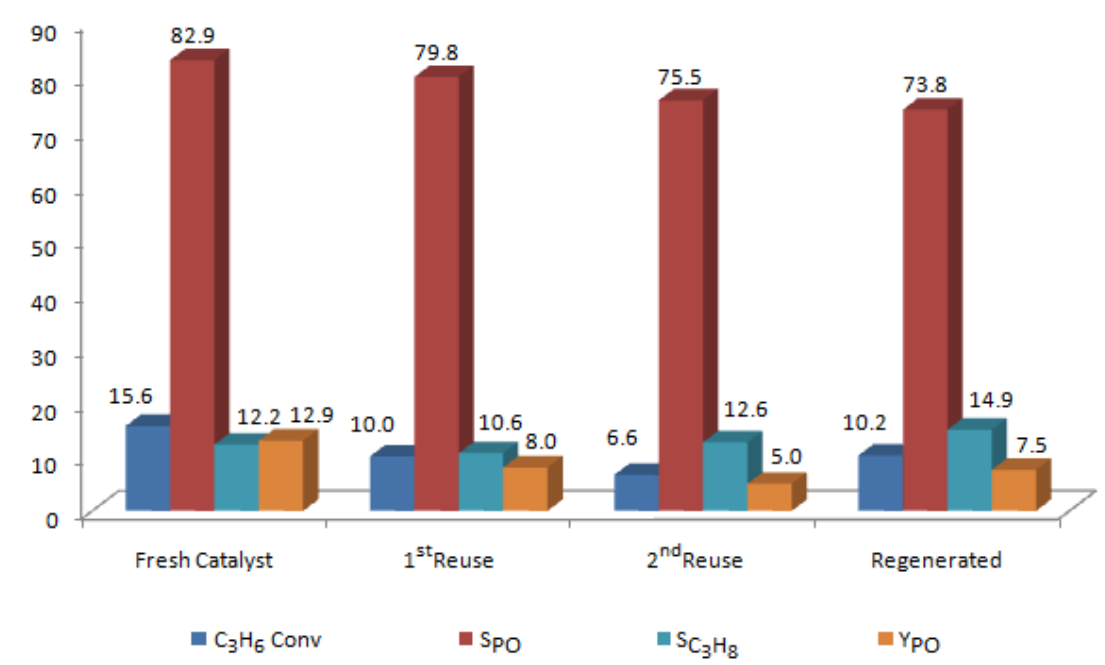

Figure 10. Stability tests carried out with in-situ generated $\mathrm{H}_{2} \mathrm{O}_{2}$ using supercritical $\mathrm{CO}_{2}$ conditions in presence of Pd10Au02@TS-1 catalyst. Reactions were carried out for $5 \mathrm{~h}$ with pressures around 75 bar and $60 \circ \mathrm{C}$, feeding $2 \mathrm{mmol}$ of propylene, $15 \mathrm{mg}$ catalyst and in presence of acidity inhibitor. Conversion, selectivity and yield values are given in $\%$. 
The results showed a decrease in the catalyst performance during the successive catalytic reuses. This trend could be related with two main reasons: i) nanoparticle aggregation during reaction and ii) partial blockage of the active sites with associated coke formation and adsorbed organic compounds produced during the reaction process.

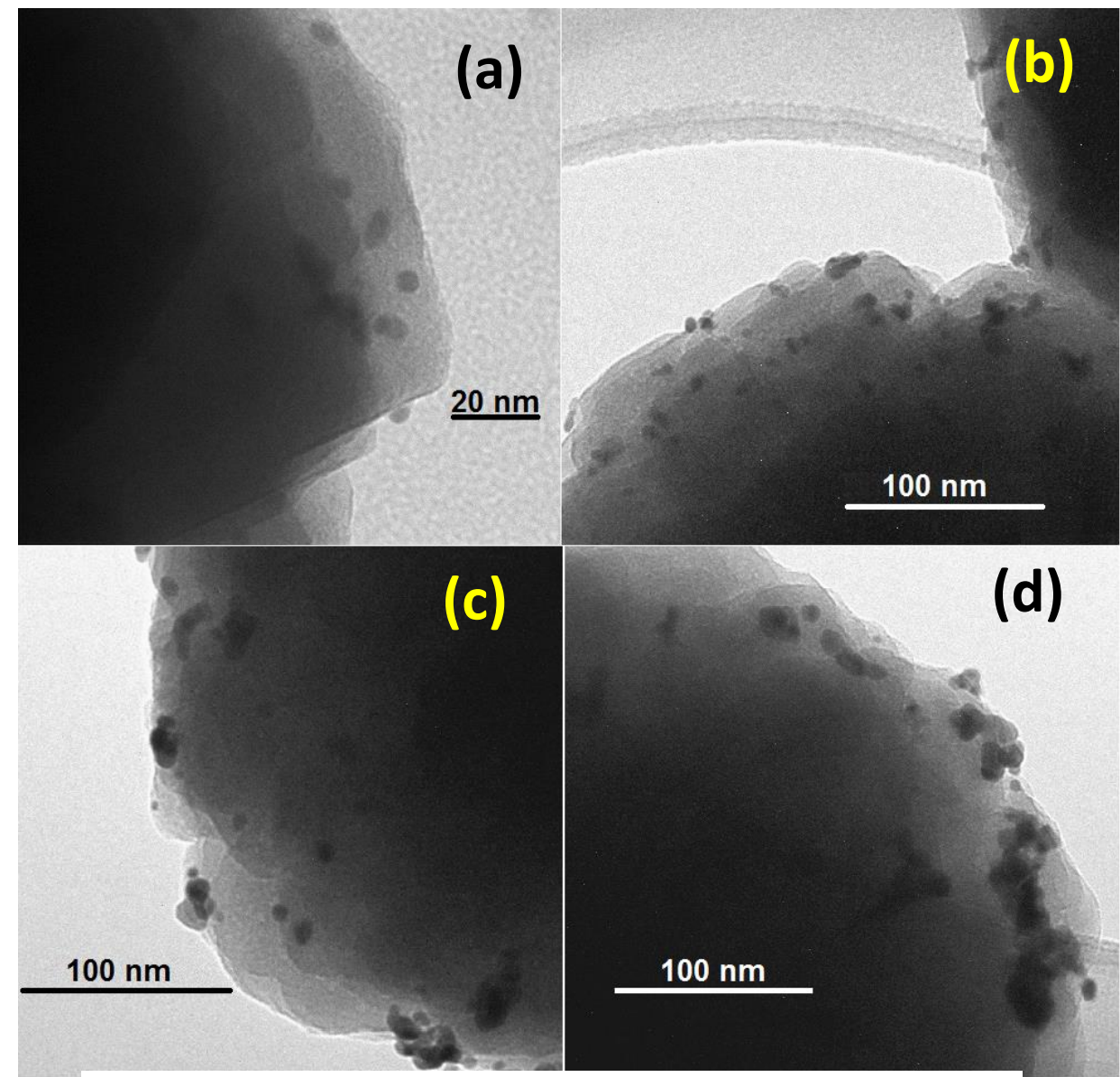

(a)
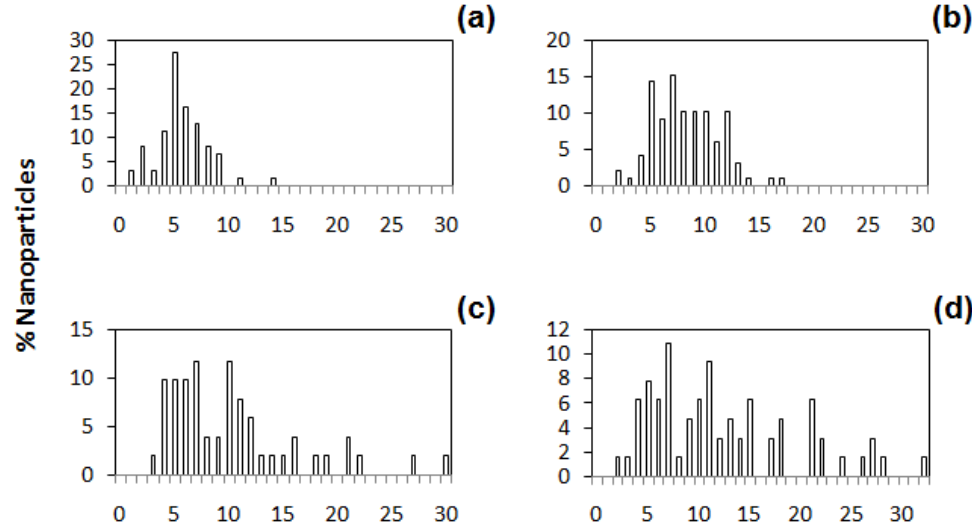

(c)

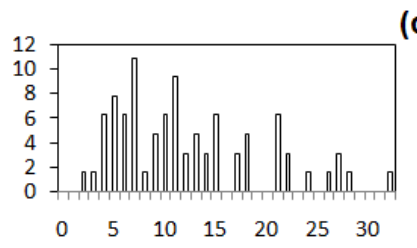

(d)

Nanoparticle Size (nm)

Figure 11. TEM micrographs and histograms of Pd10Au02@TS-1 sample: (a) fresh catalyst, (b) after $1^{\text {st }}$ use, (c) after $2^{\text {nd }}$ use and (d) after $3^{\text {rd }}$ use.

In fact, TEM micrographs of the catalyst prior and after several catalytic cycles showed that effectively the nanoparticles were agglomerated during reaction process, favoring lower catalytic activity (Figure 11). Moreover, elemental analysis of reused samples showed the 
presence up to $5 \%$ in weight of carbon, which would explain the drop in activity, due to the partial blockage of active sites together with possible diffusional problems.

It is also worth to mention that the regeneration of the catalyst through temperature treatment at $200{ }^{\circ} \mathrm{C}$ facilitated only the partial recovering of the initial catalytic activity. As we already discussed, TS- 1 catalysts require higher temperatures, close to $550 \circ \mathrm{C}$, in order to efficiently restore the initial catalytic activity [10]. However, such harsh temperature treatments cause structural alterations on the $\mathrm{PdAu}$ bimetallic nanoparticles, promoting sintering phenomena [74] which negatively affect both the formation of $\mathrm{H}_{2} \mathrm{O}_{2}$ and the PO production. For this reason, high temperature treatments were avoided, taking into account that $\mathrm{H}_{2} \mathrm{O}_{2}$ synthesis is enhanced with small nanoparticles [75] and the most preferable gold nanoparticles size for PO production is $2-5 \mathrm{~nm}[57,76,77]$.

\section{Conclusions}

Promising results have been achieved in the propylene oxide (PO) direct formation through in-situ generated $\mathrm{H}_{2} \mathrm{O}_{2}$ from hydrogen, oxygen and propylene, using high pressure conditions in batch reactor in presence of optimal bi-functional catalysts, based on gold and palladium nanoparticles supported onto nanocrystalline titanium silicalite zeolite ( $\mathrm{Pd}(\mathrm{Au}) @ T S-$ 1). These catalysts were prepared and characterized, being active and reusable to carry out the one-pot two-step process in which metallic nanoparticles catalyzed the generation of in-situ $\mathrm{H}_{2} \mathrm{O}_{2}$ as intermediate product for propylene epoxidation catalyzed by TS- 1 active matrix. In this way, propylene oxide can be obtained using only one bi-functional recyclable catalyst, allowing to carry out a consecutive reaction and avoiding additional intermediate purification steps. As consequence, higher efficiency of catalytic route would be achieved inside of more sustainable and environmental combined process. Optimization of catalytic results was achieved through the modification of different reaction parameters, including amount of metallic nanoparticles in the solid catalysts, reaction temperature and time, and effect of solvents nature on the reaction process, working always under safety supercritical $\mathrm{CO}_{2}$ conditions.

\section{Acknowledgements}

The research leading to these results has received funding from European Community's Seventh Framework Programme, through the Collaborative Project INCAS, Contract Nr. NMP2-LA-2010-245988. Authors thank additional funds from Spanish Government (MAT2014-52085-C2-1-P and Severo Ochoa Excellence Program SEV-2012-0267). 


\section{References}

[1] B. Chowdhury, K. K. Bando, J.J. Bravo-Suárez, S. Tsubota, M. Haruta, J. Mol. Catal. A Chem. 359 (2012) 21-27.

[2] D. L. Trent, Propylene oxide. In Kirk-Othmer: Encyclopedia of Chemical Technology; Wiley: New York, 2001.

[3] R. A. van Santen, C. P. M. d. Groot, J. Catal. 98 (1986) 530-539

[4] J.J. Bravo-Suárez, J. Lu, A. Takahashi, M. Haruta, S. T. Oyama, J. Catal. 232 (2005) 85-95.

[5] M. J. Climent, A. Corma, S. Iborra, ChemSusChem 2 (2009) 500-506.

[6] G. Centi, S. Perathoner, Catal. Today 138 (2008) 69-76.

[7] Shell, Eur. Patent 345856 (1989)

[8] Halcon International Inc., U.S. Patent 3350422 (1966)

[9] A.Z. Fadhel, C.L. Liotta, C.A. Eckert, Molecules 15 (2010) 8400-8424.

[10] M.G. Clerici, G. Bellussi, U. Romano, J. Catal. 129 (1991) 159-167.

[11] M. Taramaso, G. Perego, B. Notari, US Patent 4410501 (1983).

[12] K. Weissermel, H.J. Arper, Industrial Organic Chemistry, 2nd ed., 1993, VCH Publishers Inc., 141-264.

[13] C. Samanta, Appl. Catal. A: General 350 (2008) 133-149

[14] T. A. Nijhuis, M. Makkee, J. A. Moulijn, B. M. Weckhuysen Ind. Eng. Chem. Res. 45 (2006) 34473459

[15] V. Russo, R. Tesser, E. Santacesaria, M. Di Serio, Ind. Eng. Chem. Res. 52 (2013) 1168-1178

[16] Q. Liu, J.C. Bauer, R.E. Schaak, J.H. Lunsford, Angew. Chem. Int. Ed. 47 (2008) 6221-6224

[17] S. Ma, G. Li, X. Wang, Chem. Eng. J. 156 (2010) 532-539

[18] T. Hayashi , K. Tanaka, M. Haruta, J. Catal. 178 (1998) 566-575.

[19] M. Haruta, M. Date, Appl. Catal. A General 222 (2001) 427-437.

[20] B. Taylor, J. Lauterbach, W.N. Delgass, Appl. Catal. A General 291 (2005) 188-198.

[21] N. Yap, R. P. Andres, W.N. Delgass, J. Catal. 226 (2004) 156-170.

[22] W. S. Lee, M. C. Akatay, E. A. Stach, F. H. Ribeiro, W. N. Delgass, J. Catal. 287 (2012) 178-189

[23] Q. Jin, J. Bao, H. Sakiyama, N. Tsubaki, Res. Chem. Intermed. 37 (2011) 177-184

[24] A. K. Sinha, S. Seelan, S. Tsubota, M. Haruta, Angew. Chem. Int. Ed. 43 (2004) 1546-1548

[25] J. Lu, X. Zhang , J.J. Bravo-Suárez, T. Fujitani, S.T. Oyama, Catal. Today 147 (2009) 186-195

[26] T. Liu, P. Hacarlioglu, S. T. Oyama, M. F. Luo, X. R. Pan, J. Q. Lu, J. Catal. 267 (2009) 202-206

[27] J. Huang, E. Lima, T. Akita, A. Guzmán, C. Qi, T. Takei, M. Haruta, J. Catal. 278 (2011) 8-15

[28] B.E.V. Schröder, H. Jansen, H. Schulze, Chem. Eng. Technol. 27 (2004)847-851.

[29] V. Paunovic, V. Ordomsky, M. F. Neira D’Angelo, J. C. Schouten, T. A. Nijhuis, J. Catal. 309 (2014) 325-332

[30] C. M. Piqueras, J. García-Serna, M.J. Cocero, J. Supercrit. Fluids 56 (2011) 33-40 
[31] D. Hancu, E.J. Beckman, Green Chem. 3 (2001) 80-86

[32] O. Pande, J. Tonheim, Proc. Safety Progr. 20 (2001) 37-39

[33] Q. Chen, E. J. Beckman, Green Chem. 9 (2007) 802-808

[34] Y. Chen, Y. Wu, Y. Zhang, L. Long, L. Tao, M. Yang, N. Tang, J. Mol. Catal. A: Chem. 352 (2012) 102109

[35] Q. Chen, E.J. Beckman, Green Chem. 10 (2008) 934-938

[36] A. Prieto, M. Palomino, U. Díaz, A. Corma, Catal. Today 227 (2014) 87-95

[37] I. Moreno, N. F. Dummer, J. K. Edwards, M. Alhumaimess, M. Sankar, R. Sanz, P. Pizarro, D. P. Serrano, G. J. Hutchings, Catal. Sci. Technol. 3 (2013) $2425-2434$

[38] W. Laufer, W.F. Hölderich, Appl. Catal. A Gen 213 (2001) 163-171

[39] R.B. Khomane, B.D. Kulkarni, A. Paraskar, S.R. Sainkar, Mater. Chem. Phys. 76 (2002) 99-103

[40] N. Dimitratos, J.A. Lopez-Sanchez, J. M. Anthonykutty, G. Brett, A. F. Carley, R. C. Tiruvalam, A. A. Herzing, C. J. Kiely, D. W. Knight , G. J. Hutchings, Phys. Chem. Chem. Phys. 11 (2009) 4952-4961

[41] S. J. Gregg, K. S. W. Sing, Adsorption, Surface Area and Porosity, Academic Press, London (1982).

[42] K. S. W. Sing, D. H. Everett, R. A. W. Haul, L. Moscou, R. A. Pierotti, J. Rouquerol, T. Siemieniewska, Pure Appl. Chem. 57 (1985) 603-619.

[43] E. P. Barrett, L. G. Joyner, P. P. Halenda, J. Am. Chem. Soc. 73 (1951) 373-380.

[44] E. J. Beckman, J. Supercrit. Fluids 28 (2004) 121-191

[45] B. Taylor, J. Lauterbach, W. N. Delgass, Catal. Today 123 (2007) 50-58

[46] A. Corma, U. Díaz, M.E. Dómine, V. Fornés, Angew. Chem. Int. Ed. 39 (2000) 1499-1501.

[47] H. E. Swanson, E. Tatge, Standard X-ray diffraction powder patterns. Vol. I, Data for 54 inorganic substances, National Bureau of Standards, Washington (1953) http://babel.hathitrust.org/cgi/pt?id=mdp.39015077578352;view=1up;seq=1

[48] L. W. McKeehan, Phys. Rev. 21 (1923) 334-342

[49] W. Zhao, V. Fierro, C. Zlotea, M.T. Izquierdo, C. Chevalier-César, M. Latroche, A. Celzard, Int. J. Hydr. Energy 37 (2012) 5072-5080

[50] A. M. Venezia, V. La Parola, G. Deganello, B. Pawelec, J. L. G. Fierro, J. Catal. 215 (2003) 317-325

[51] G. N . Vayssilov, Rev. Sci. Eng. 39 (1997) 209-251

[52] M.R. Boccuti, K.M. Rao, A. Zecchina, G. Leofanti, G. Petrini, Stud. Surf. Sci. Catal. 48 (1989) 133-144

[53] A. Zecchina, G. Spoto, S. Bordiga, A. Ferrero, G. Petrini, G. Leofanti, M. Padovan, Stud. Surf. Sci. Catal. 69 (1991) 251-258

[54] G. Bellussi, A. Carati, M. G. Clerici, G. Madolinelli, R. Millini, J. Catal. 133 (1992) 220-230

[55] J. Lu, X. Zhang, J. J. Bravo-Suárez, K. K. Bando, T. Fujitani, S. Ted Oyama, J. Catal. 250 (2007) 350-359

[56] E. E. Stangland, B. Taylor, R. P. Andres, W. N. Delgass, J. Catal. 232 (2005) 38-42

[57] C. Qi, J. Huang, S. Bao, H. Su, T. Akita, M. Haruta, J. Catal. 281 (2011) 12-20

[58] L. Cumaranatunge, W. N. Delgass, J. Catal. 232 (2005) 38-42

[59] G. F. Thiele, E. Roland, J. Mol. Catal. A. Chem. 117 (1997) 351-356 
[60] R. Burch, P.R. Ellis, Appl. Catal. B: Env. 42 (2003) 203-211

[61] V.V. Krishnan, A.G. Dokoutchaev, M.E. Thompson, J. Catal. 196 (2000) 366-374

[62] V.R. Choudhary, C. Samanta, J. Catal. 238 (2006) 28-38

[63] J. K. Edwards, B. E. Solsona, P. Landon, A. F. Carley, A. Herzing, C. J. Kiely, G. J. Hutchings, J. Catal. 236 (2005) 69-79

[64] J. K. Edwards, S. J. Freakly, A. F. Carley, C. J. Kiely, G. J. Hutchings, Acc. Chem. Res. 47 (2014) 845-854

[65] G. Centi, S. Perathoner, S. Abate, Modern Heterogeneous Oxidation Catalysis: Design, Reactions and Characterization, Wiley-VCH,Weinheim, 2009, pp.253.

[66] H. C. Ham, G. S. Hwang, J. Han, S. W. Nam, T. H. Lim, J. Phys. Chem. C 113 (2009) 12943-12945

[67] W. Laufer, R. Meiers, W. Hölderich, J. Mol. Catal. A Chem. 141 (1999) 215-221

[68] R. Meiers, W.F. Hölderich, Catal. Lett. 59 (1999) 161-163

[69] J. Gaudet, K.K. Bando, Z. Song, T. Fujitani, W. Zhang, D.S. Su, S.T. Oyama, J. Catal. 280 (2011) 40-49

[70] M. Du, G. Zhan, X. Yang, H. Wang, W. Lin, Y. Zhou, J. Zhu, L. Lin, J. Huang, D. Sun, L. Jia, Q. Li, J. Catal. 283 (2011) 192-201

[71] G. Zhan, M. Du, D. Sun, J. Huang, X. Yang, Y. Ma, A. R. Ibrahim, Q. Li, Ind. Eng. Chem. Res. 50 (2011) 9019-9026

[72] G. Li, J. Edwards, A. F. Carley, G. J. Hutchings, Catal. Today 114 (2006) 369-371

[73] V. R. Choudhary, P. Jana, Appl. Catal. A 352 (2009) 35-42

[74] R. C. Tiruvalam, J. C. Pritchard, N. Dimitratos, J. A. Lopez-Sanchez, J. K. Edwards, A. F. Carley, G. J. Hutchings, C. J. Kiely, Faraday Discuss. 152 (2011) 63-86

[75] J. K. Edwards, A. F. Carley, A. A. Herzing, C. J. Kiely, G. J. Hutchings, Faraday Discuss. 138 (2008) 225239

[76] A. K. Sinha, S. Seelan, S. Tsubota, M. Haruta, Top. Catal. 29 (2004) 95-102

[77] B. Chowdhury, J. J. Bravo-Suárez, M. Date, S. Tsubota, M. Haruta, Angew. Chem. Int. Ed. 45 (2006) 412-415 